\title{
THE EFFECT OF CHEWING GUM ON TOBACCO WITHDRAWAL
}

\author{
By \\ LEE COHEN \\ Bachelor of Arts \\ University of California, San Diego \\ La Jolla, California \\ 1994
}

Submitted to the Faculty of the

Graduate College of the

Oklahoma State University in partial fulfillment of the requirements for the Degree of MASTER OF SCIENCE May, 1996 


\section{OKR.AHOMA STATE UNIVERSITY}

THE EFFECT OF CHEWING GUM ON

TOBACCO WITHDRAWAL

Thesis Approved:

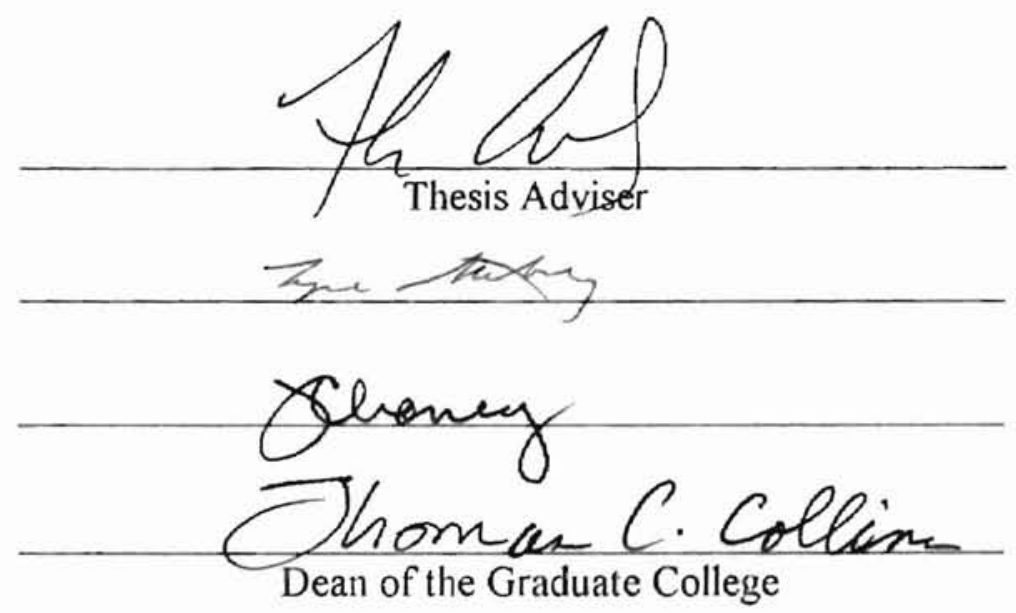




\section{ACKNOWLEDGMENTS}

I wish to express my sincere appreciation to my advisor, Dr. Frank Collins for his instruction and supervision during the course of this study. His patience and mentorship throughout this endeavor has been invaluable to me and has made it possible for me to accomplish this goal. I would also like to express my thanks to my committee members, Dr. John Chaney, and Dr. Lynne Steinberg, for their time, comments, and recommendations that helped to make this study a success.

I would also like to thank my mom, Hazel, my dad, Fred, and my brother, Alan for their continuous support and encouragement throughout my academic career. I am sure that without their assistance and guidance I would have never been able to achieve my goals.

Finally, I would like to thank the Department of Psychology, not only for providing me with the opportunity to further my education, but also for this research opportunity and their financial support over the past two years. 


\section{TABLE OF CONTENTS}

Chapter

Page

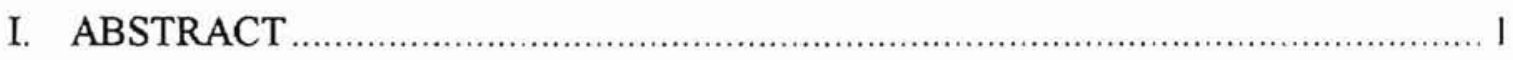

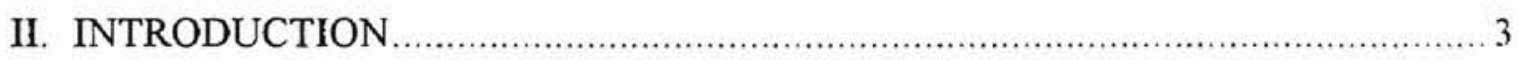

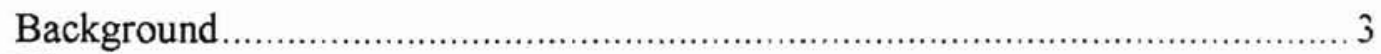

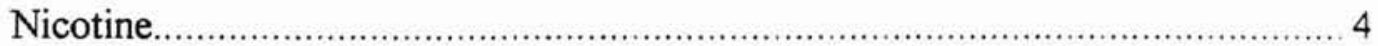

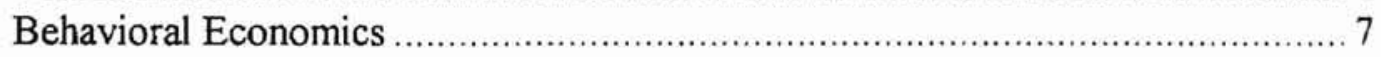

Application of Behavioral Economics ...................................................... 11

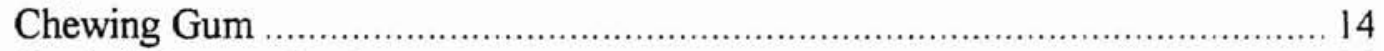

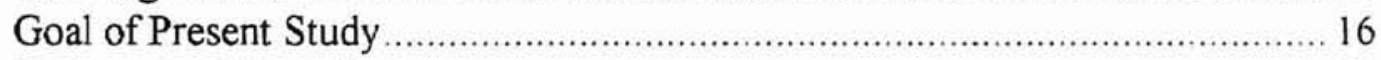

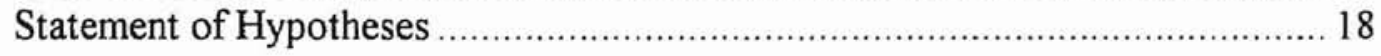

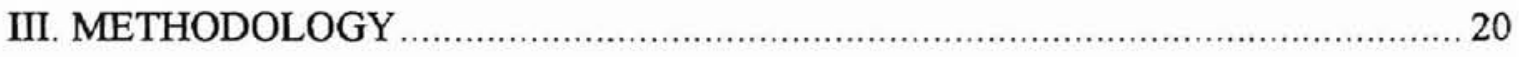

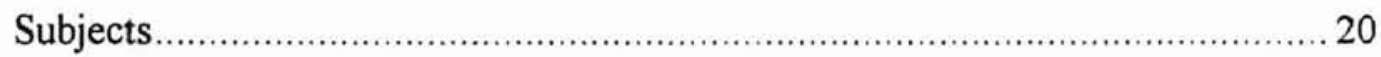

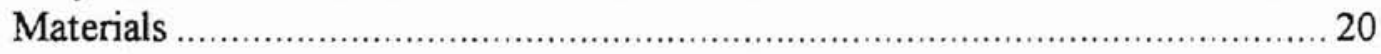

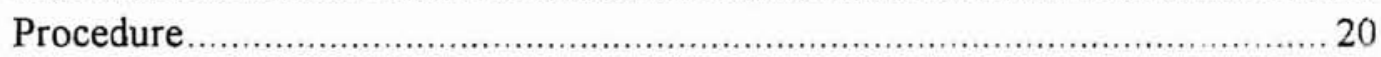

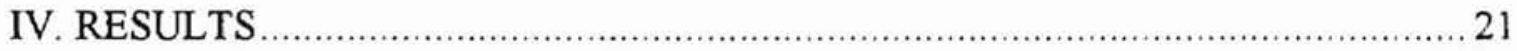

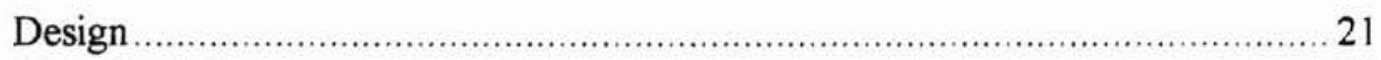

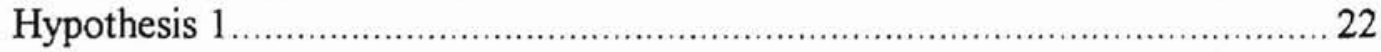

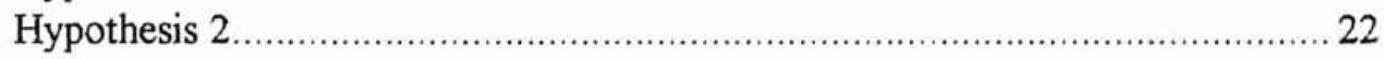

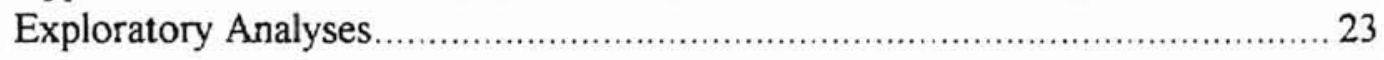

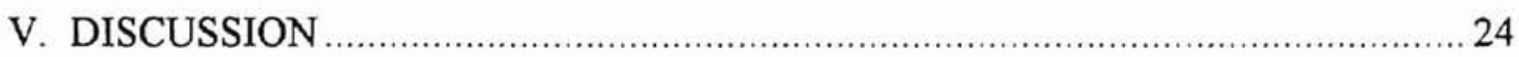

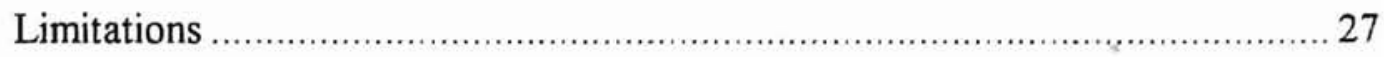

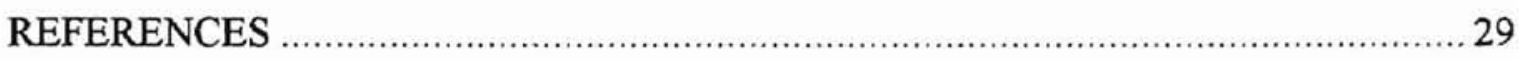

APPENDIX - TOBACCO WITHDRAWAL SYMPTOM CHECKLIST ...................... 34

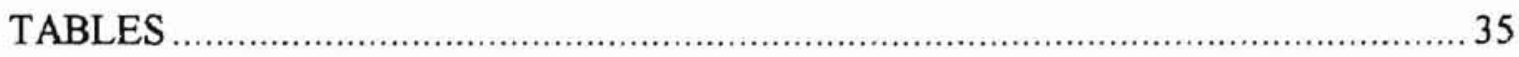




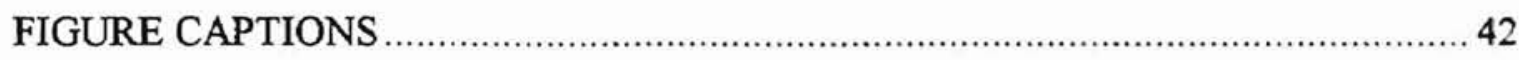

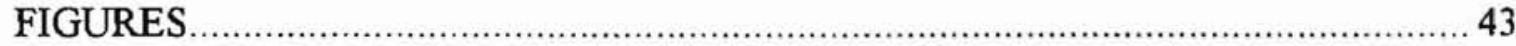




\section{LIST OF TABLES}

Table

Page

I. t-tests for Differences Between Conditions at Baseline ......................................... 35

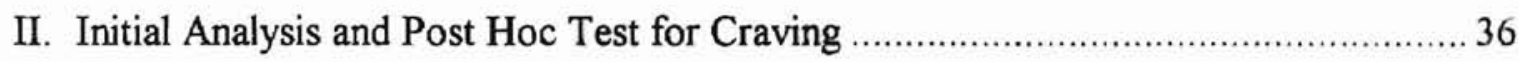

III. Initial Analysis and Post Hoc Test for Total Withdrawal .......................................... 37

IV. Exploratory Analyses for the Remaining Symptoms on the

Tobacco Withdrawal Symptoms Checklist ............................................... 38 


\section{LIST OF FIGURES}

Figure

Page

1. Mean Craving Score for Gum and No Gum Condition

at Time 1 and Time 2 .

2. Mean Total Withdrawal Score for Gum and No Gum Conditions

at Time 1 and Time 2

3. Mean Anxiety Score for Gum and No Gum Conditions

at Time 1 and Time 2 .

4. Mean Difficulty Concentrating Score for Gum and No Gum Condition

at Time 1 and Time 2

5. Mean Drowsiness Score for Gum and No Gum Conditions

at Time 1 and Time 2

6. Mean Fatigue Score for Gum and No Gum Conditions

at Time 1 and Time 2 .

7. Mean Headache Score for Gum and No Gum Conditions

at Time 1 and Time 2

8. Mean Hunger Score for Gum and No Gum Conditions

at Time 1 and Time 2

9. Mean Intestinal Disturbance Score for Gum and No Gum Condition

at Time 1 and Time 2

10. Mean Impatience Score for Gum and No Gum Conditions

at Time 1 and Time 2

11. Mean Insomnia Score for Gum and No Gum Conditions

at Time 1 and Time 2 . 
1. Mean Irritability Score for Gum and No Gum Condition

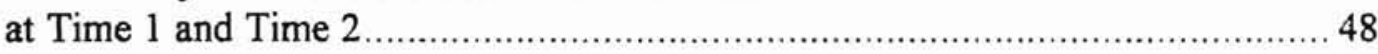

2. Mean Restlessness Score for Gum and No Gum Conditions

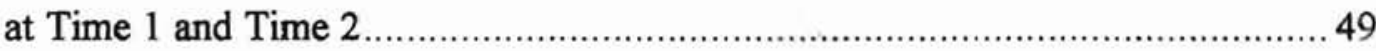




\begin{abstract}
The relationship between cigarette smoking and gum chewing is important to psychological research. Wrigley's has long believed that when smokers are in situations where smoking is prohibited, chewing gum will lessen their craving to smoke. Due to this belief, they have targeted the smoking population stating, "When you can's smoke, chew gum." Unfortunately, this belief has not been backed up with scientific evidence. The purpose of this study was to learn more about why gum might help when a person can't smoke. Nicotine withdrawal symptoms were compared in smokers who were asked to abstain from smoking for a short period of time, where half of the subjects were given access to chewing gum during the period of abstinence and the other was not.
\end{abstract}

Twenty heavy smokers (defined as 16 or more per day) served as subjects. Upon arrival at the lab, subjects were asked to smoke a cigarette and were then asked to rate their withdrawal symptoms using the Tobacco Withdrawal Symptom Checklist (WSC). Next subjects were asked to watch a movie of their choice without smoking. At the end of the movie subjects' withdrawal was again measured and each subject was asked to remain in the lab for a short period of time ( 30 minutes) where they were asked to continue to abstain. At the end of the 30 minute time period, subjects were asked to rate their withdrawal one last time. All sessions were identical, except that the experimental group was given access to chewing gum while the control group was not.

Results from this study indicate that gum chewing reduces craving and helps with withdrawal when a nicotine dependent person cannot smoke. The results do not suggest that chewing gum will allow a person to avoid withdrawal altogether. Withdrawal was clearly seen in all the subjects who participated in this study, yet it was observed that those 
subjects that were asked to chew gum experienced significantly less withdrawal than their no-gum counterparts. Interestingly, the "craving" that smokers often report having for a cigarette when their blood nicotine levels drop, appeared to decrease if they were given access to chewing gum during the time in which they were asked to withhold from smoking. This drop in craving however, is small. 


\section{The Effect of Chewing Gum on Tobacco Withdrawal}

It is estimated that $32 \%$ of the American public smoked cigarettes in the past year, and nearly $27 \%$ have smoked cigarettes in the past month (National Institute on Drug Abuse [NIDA], 1994). Chronic cigarette smoking is associated with a number of serious medical illness including, cancer, coronary heart disease, and stroke. Given the high rate of cigarette consumption and the health problems related to their continued use, it should come as no surprise that cigarette smoking is the number one preventable cause of death in our society. It is directly responsible for approximately 390,000 deaths each year in the United States alone, which accounts for more than one out of every six deaths in our country (U.S. Department of Health \& Human Services [DHHS], 1990). Despite the wellknown health hazards, more than 50 million Americans continue to use tobacco products (US DHHS, 1988). Thus, smoking cessation could prevent a large number of deaths each year and defer the onset of a large number of these terminal illnesses. Many smokers find it difficult to stop using cigarettes and this is confirmed by the staggering rate that exsmokers relapse. Of the seventeen million smokers that try to quit each year, fewer than I out of 10 actually succeed (Kessler, 1994).

During the past two decades, smoking cessation research has advanced notably in many different areas. For example, current designs and evaluations of treatments have become more theory driven, improved therapy process measures are used, and a variety of practical problems that were once a problem for researchers (i.e. subject attrition), have been reduced (US DHHS, 1988). Such improvements are recent however, and identify only a few published studies. Taking this information into account, it is important to note that there are still aspects of cessation programs that have remained fairly stable over time, 
the most prominent being the low success rate (Lichtenstein \& Glasgow, 1992). It is believed that smokers relapse for a variety of reasons, the main one being to relieve the withdrawal symptoms associated with smoking cessation. It is known that the signs and symptoms of tobacco withdrawal varies from person to person, so the development of a successful, uniform cessation program that focuses on relieving withdrawal symptoms for all smokers is not likely. It makes sense therefore, that a treatment program that focuses on the most common symptom of withdrawal, namely the "craving" that a smoker has for a cigarette, would be the most beneficial since it could potentially help the greatest number of people. The study proposed in this paper was designed to assess whether chewing gum could decrease the "craving" associated with smoking cessation.

The following review will first present evidence which illustrates the importance of nicotine for maintaining smoking behavior. This section will also discuss the criteria necessary to define drug dependence and the behavioral and pharmacologic process that involves the maintenance of desired levels of nicotine in the body. Second, concepts from behavioral economic theory will be presented in order to illustrate how this theory can give a better understanding of drug taking behavior. Third, studies which have applied behavioral economic theory to examine drug-taking behavior will be reviewed Fourth, the psychological and physiological factors involved in gum chewing will be addressed. Last, the goals and hypotheses of the proposed studies will be addressed.

\section{Nicotine}

A large body of research has shown that smoking cigarettes is addicting and that nicotine is the agent in cigarettes that leads to addiction (US DHHS, 1988). In the scientific community, the terms "drug addiction" and "drug dependence" are synonymous 
in that both terms refer to the behavior of repeatedly ingesting mood-altering substances by individuals. The World Health Organization and the American Psychiatric Association have developed a set of criteria to determine whether tobacco-delivered nicotine is addicting. This criteria for drug dependence includes primary and additional indicators. The three primary criteria are sufficient to define drug dependence. First, highly controlled or compulsive use indicates that drug-seeking and drug-taking behavior is driven by strong and often irresistible urges. It can continue despite a true desire to quit or even repeated attempts to quit. Second, the drug has psychoactive or mood-altering effects. Last, the drug reinforces behaviors related to obtaining and consuming the drug itself. Therefore, the psychoactive chemical must be capable of functioning as a reinforcer that can directly strengthen behavior leading to further drug ingestion.

Additional criteria are often used to help characterize drug dependence. Some of these criteria are associated with the drug-taking behavior itself. These include: (a) the behavior may develop into regular stereotypic patterns of use, (b) the use of the drug despite its harmful effects, (c) relapse following abstinence, and (d) recurrent drug cravings. The other additional criteria are associated with the control that they have over the behaviors that increase the likelihood of harm to the individual by contributing to the regularity and overall level of the drug intake. These include, tolerance, physical dependence, and pleasant or euphoriant effects.

Tobacco use involves several biobehavioral processes of drug dependence, including nicotine reinforcement, however the initiation and maintenance of this dependence may be supported by other actions of nicotine. For example, some cigarette smokers report that smoking helps them to think better, to cope with stress, and to keep 
body weight under control (US DHHS, 1988). The belief that tobacco use has these effects may contribute to initiation, maintenance, and relapse.

Cigarette smoking is an orderly behavioral and pharmacologic process that involves maintenance of the desired levels of nicotine in the body. Thus, the role of nicotine in controlling tobacco self-administration is similar to other addictive drugs (i.e., ethanol) in the use of their respective products (i.e., alcoholic beverages). It is less clear however, if the behavior-controlling pharmacologic properties of nicotine share critical dependence-producing properties with these other drugs. Standardized testing procedures have been used in both animal and human studies to determine if a drug is dependence producing (US DHHS, 1988). On the basis of these testing procedures, four general kinds of behavior-modifying drug effects seem to be distinct. These effects include: (a) drugs produce interoceptive stimulus effects, which means they produce effects that a person or animal can distinguish from the non-drug state; (b) drugs serve as rewards, where the presentation of the drug itself produces a strengthening of the behaviors which originally led to its presentation; (c) drugs serve as unconditioned stimuli, where they can directly elicit various responses, and in the ensuing period, these responses can be elicited by stimuli that are associated with the drug, including the presence of environmental or internal cues; and (d) drug administration or abstinence can also serve as punishers or aversive stimuli.

Each of these four behavior-modifying drug effects can be classified às a reinforcement model. The first three can be though of in terms of positive reinforcement models, and the last as a negative reinforcement model. The primary biobehavioral mechanism by which drugs maintain drug seeking is by functioning as a positive reinforcer. 
More simply, a drug, such as nicotine, can serve as a stimulus that strengthens the behavior that leads to its own delivery. Even dependence-producing drugs however, do not have uniform positive reinforcing effects and may even be aversive under some conditions. Negative reinforcement is a mechanism by which drugs modify behavior and may be important in increasing the amount of control put forth by the drug over the individual. For example, if a person reduces his/her nicotine intake it is likely that he/she will experience one or more withdrawal symptoms which include, depressed mood, insomnia, irritability, anxiety, difficulty concentrating, restlessness, decreased heart rate, and weight gain. Thus, many individuals who use nicotine take it in order to avoid or relieve withdrawal symptoms, for instance, when they wake up in the morning or have been in a situation where the use of nicotine has been restricted (i.e., at the movie theater).

\section{Behavioral Economics}

Behavioral economics is the application of economic theory to the analysis of behavior (DeGrandpre, Bickel, Hughes, \& Higgins, 1992). Since the early 1970's behavioral economic theory has provided a useful conceptualization for analyzing behavior (Hursh, 1984). One such conceptualization has been borrowed from the area of microeconomics called consumer demand theory which looks at the relationship between the price of a consumer good and the demand for that consumer good. It is important to note that in behavioral economics, the economic terms "purchased", "consumer good", and "price" are synonymous with the behavioral terms "self-administered", "reinforcer", and "response requirement".

One of the most fundamental principles of behavioral economics is the demand law. This law states that, "all else being equal, total consumption decreases as price 
increases" (Allison, 1979). This law holds true with regard to the effects of response requirement, or what a person must do to obtain a drug, on drug self-administration. More simply, drug consumption decreases as response requirement increases. Therefore, in behavioral terms, demand is defined as the amount of reinforcer that is self-administered versus the response requirement to obtain the reinforcer (DeGrandpre et al., 1992). The demand curve is related to the concept of demand. For this curve, the amount of the consumer good purchased is plotted on the Y-axis and the price of the consumer good is plotted on the $\mathrm{X}$-axis.

Elasticity is a second important concept that is taken from the field of economics and is applied to behavioral theory. This term refers to the degree to which the consumption of a specific good decreases as response requirement, or price, increases (DeGrandpre et al., 1992). A consumer good can be considered either a luxury or a necessity based on that goods elasticity. That is, when the consumption of a reinforcer changes greatly with an increased cost, it is said to be a luxury or an elastic commodity. On the other hand, when the consumption of a reinforcer changes only a little with increased cost it is said to be a necessity or an inelastic commodity.

The third important concept that behavioral economics borrows from economics is cost, or unit price. Unit price can be thought of as the response requirement divided by the reinforcer size (Hursh, Raslear, Shurtleff, Bauman, \& Simmons, 1988). Unit price can be increased by one of two ways, by increasing the response requirement, or by decreasing the size of the reinforcer. According to behavioral economic theory, consumption should be the same if the unit price is the same, regardless of the components that make up that unit price. For example, a researcher could use several response 
requirements and several doses. Thus a unit price of 6 could be derived by various combinations of fixed-ratio (FR) response requirements and deliveries of the reinforcer. For example, when a person is permitted to smoke one cigarette for every six correct answers given (a fixed-ratio schedule of $6[$ FR-6]) the unit price of the cigarette remains constant, despite the number of correct responses. More simply, the unit price of 6 remains unchanged regardless of the constituents that make up that unit price since there are many combinations that will yield 6 (i.e., $6 / 1,12 / 2,24 / 4$ ).

For most reinforcers studied, as unit price increases, consumption of that reinforcer initially changes little and then at some unit price it falls rapidly (Bickel. DeGrandpre, Hughes, \& Higgins, 1991). This has been shown recently in a study by Bickel et al. (1991) where he examined human cigarette smokers. For this study, the effects of various combinations of dose (1,2, or 4 puffs) and response requirement (FR 200,400 , and 1600) on nicotine consumption were examined in 3 hour sessions. In general, the findings proved that self-administration remained stable until high unit prices were hit, and then decreased rapidly, and also that different combinations of dose and response requirement in which the end result was the same unit price produced similar amounts of responding and drug consumption.

One last concept that must be addressed in regard to behavioral economic theory revolves around the accompaniment of other reinforcers in the environment. The availability of alternative reinforcers (consumer goods) directly affects the consumption of a particular consumer good, and it is at this point that an understanding of substitute and complement reinforcers comes in handy. Commodities are said to be substitutes when the change in the price of one commodity changes the consumption of another commodity 
oppositely (Bickel, Hughes, DeGrandpre, Higgins, \& Rizzuto, 1992). For example, when a smoker goes to see a movie and is not permitted to smoke while in the theater, the price of smoking is great (i.e., removal from the theater), and the smoker may choose other less costly reinforcers found at the snack bar. Typically, the smoker stays away from sweets. but given the high cost of smoking he/she substitutes candy, a lower priced commodity, for cigarettes. Hence, an increase in the price of smoking, causes an increase in the consumption of candy. It has been suggested (Hursh \& Bauman, 1987) that commodities are more likely to be substitutes when they share similar properties and effects. In the example above, both candy (sugar) and cigarettes share some common properties in that they are administered orally, they require some movement of the jaw muscles, and they offer stimulant effects to the consumer.

In contrast, a complementary relationship between reinforcers is said to exist when an increase or decrease in the consumption of one consumer good results in a similar change in the other reinforcers (Bickel et al., 1992). To better conceptualize this relationship, consider the association between the consumption of hot dogs and hot dog buns. If the price of hot dogs becomes too great; hot dog consumption should decrease, and presumably hot dog bun consumption would decrease as well. The converse is also true. If the price of hot dogs suddenly dropped to a point where people began to consume a greater number of hot dogs, it is also probable that the consumption of hot dog buns will increase as well. Hursh and Bauman (1987) noted that consumer goods are more likely to be complements the more that both are necessary to produce the desired state, or effect. Expanding on the above example, imagine a hot dog barbecue with out hot dog buns. Eating hot dogs out doors becomes much more inconvenient without the buns. 


\section{Application of Behavioral Economics}

Numerous researchers have applied behavioral economic theory to different types of consumer goods, including drugs, and have found this perspective to be useful in explaining the relationships between reinforcing stimuli. Studies done in laboratory settings indicate that both the use of coffee and alcohol increase the number of cigarettes that a smoker will smoke in a given time period (Epstein \& Jennings, 1986). Keeping in line with behavioral economics, this finding suggests that these commodities have complementary relationships.

Marshall, Epstein, and Green (1980), randomly assigned coffee drinking smokers to one of four groups where they were given $0,1,2$, or 3 cups of coffee during two onehour sessions, during which time they were asked to work on crossword puzzles. Results showed that subjects who received coffee in any amount smoked more than the subjects who were not given access to coffee. Moderate and low rate smokers from the previous study were then examined further in a second study designed to assess the aspects of coffee that influence smoking behavior. In this study, subjects were randomly assigned to one of five groups in which they were provided with no drink, water, Potsum (a coffee substitute), caffeinated, or decaffeinated coffee. Results from this study showed that subjects who were given caffeinated or decaffeinated coffee smoked more than subjects in the Potsum, no drink or water control groups. These results provide experimental evidence of the role of coffee in setting the occasion for smoking, as well as ruling out the presence of a liquid or caffeine as the important aspect of coffee in influencing smoking.

In a follow-up study (Marshall, Green, Epstein, Rogers, \& McCoy, 1980), the relationship between cigarette smoking, coffee drinking, and urinary $\mathrm{pH}$ was examined. 
Previous research by Schacter et al. (1977), found that increased urine acidity causes increased excretion of nicotine in the urine. This urinary $\mathrm{pH} /$ nicotine excretion phenomenon is believed to be a physiological mechanism that could influence cigarette smoking behavior since the more nicotine one excretes through urine, the more that person will need to smoke to regulate his/her nicotine levels. It has been suggested that coffee has an acidifying effect on urine, and therefore may effect urinary $\mathrm{pH}$ (Marshall et al., 1980). Thus, urine acidity levels were manipulated to see if this level would directly effect cigarette smoking. The eight subjects in this study participated in each of the four conditions in which they received: water, coffee, coffee plus sodium bicarbonate, or coffee plus ascorbic acid. The results from this study were in line with the previous studies since it was found that subjects smoked more cigarettes in a one hour session when they were in one of the three coffee conditions. Coffee itself did not have an effect of increasing urine acidity, so increased urine acidity cannot account for the smoking increases observed in this study.

Results from the above studies show the importance of the repeated relationships between environmental stimuli (coffee) and smoking. Thus, if drinking coffee reliably influences smoking behavior, the regulation of one's coffee intake would be a necessary step in the regulation of one's smoking behavior. On a similar note, laboratory studies have examined the smoking-alcohol relationship and have provided comparable results. Epstein and Jennings (1986), demonstrated that alcohol, like coffee, can set the occasion for increased smoking.

Griffiths, Bigelow, and Liebson (1976), looked at the effect of alcohol (ethanol) on the cigarette smoking of alcoholic subjects. In this study, cigarettes were obtained either 
by request or by operation of a lever (FR 5 or 10) during daily 6 hour sessions. The sessions were randomized so that on some days the subjects drank orange juice alone and on other days they drank orange juice plus ethanol. During the sessions in which there was ethanol added to the orange juice, the rate of cigarette smoking was found to be significantly higher than the days in which there was no ethanol added to the orange juice. Results from this study suggest that smoking and ethanol serve as compliments to each other, which as stated earlier is when an increase in the consumption of one consumer good (ethanol) is associated with the increase in another consumer good (cigarette smoking).

In addition to smoking and alcohol having a complementary reiationship, support has been found for the substitutability or these two drugs. Perkins, Epstein, Sexton, and Pastor (1990), examined the consumption of alcohol, coffee, soda, and sweets (sweet, high-fat foods) of seven young female smokers over a three week period. This study involved baseline smoking (week 1), complete smoking cessation (week 2), and resumption of smoking (week 3). Results showed that there was an increased intake of sweets, and to a lesser degree, alcohol after smoking cessation which was reversed upon resumption of smoking. No significant changes across weeks were found with regard to the other substances.

The findings from the above study show that smoking cessation, a behavior change that promotes health, may lead to changes in the consumption of other substances (e.g., sweets, alcohol), that may themselves have negative effects on one's health. Therefore, sweets and alcohol appear to be substitutes for smoking, that is, the change in the consumption of cigarette smoking changes the consumption of sweets \& alcohol in an 
opposite way. When smoking was not available to the subjects (the unit price of smoking became too great), alternative consumer goods were used to replace cigarettes.

Alternative reinforcers other than sweets and alcohol, such as soda and TV viewing, were also available to the subjects however, were not shown to act as substitutes. This implies that the effect of smoking cessation on alternative reinforcers is specific, not general in nature. So, if the findings of all the studies that examined the relationship between alcohol and cigarette smoking are taken into account, one can clearly see that alcohol can serve as both a substitute and a compliment to cigarette smoking

\section{Chewing Gum}

There are many theories as to why humans chew gum and other nonfood items, however no theory has sufficient evidence to back up its claim. One panel of psychiatrists and psychologists suggest that the top three reasons people chew gum are: (a) to relieve feelings of loneliness and boredom, (b) relief from tension by discharging nervous energy, and (c) to provide a quick, socially acceptable outlet for anger and irritation (Hendrickson, 1976). In addition, various studies have shown that gum chewing alleviates thirst and hunger, helps workers concentrate, and keeps people alert (Hendrickson, 1976).

There has been a great deal of research that has examined the advantages of gum chewing. This research was inspired by the establishment of the Wrigley-Beech-Nut Fellowship at Northwestern University during the Great Depression, and this industrysponsored grant was set up for the sole purpose of researching the physiological effects of gum chewing.

Dr. Robert H. Veitch, Director of the Deafness Clinic at the Massachusetts Osteopathic Hospital recommended that anyone experiencing deafness during common 
colds should try chewing gum several hours a day for relief. Medical authorities point out that the chewing of gum induces frequent swallowing, which opens the air passages, allowing air pressure to be equalized inside the ear (Hendrickson, 1976).

Recently, it has been suggested in advertisements that chewing gum may serve as an alternative to smoking, however empirical studies examining this notion have not been undertaken. Given that nicotine itself has been shown to be an adequate positive reinforcer for animals (Goldberg, Spealman, \& Goldberg, 1981) and humans (Henningfield, Miyasato, \& Jasinski, 1983), it would make sense that in order for gum chewing to serve as a substitute for smoking the mere act of chewing gum must also serve as a positive reinforcer. Clearly, there is something reinforcing about chewing gum, as evidenced by the large number of people who chew gum on a daily basis, however it is not clear what aspect of gum chewing accounts for the reinforcing effects experienced by gum chewers.

One hypothesis that could account for why some people believe that gum chewing is an adequate substitute for cigarette smoking is that both of these actions are reinforcing due to the fact that they both stimulate the jaw muscles. It has been shown that facial muscles constitute an emotional output system and are closely related to the experience of emotion (Dimberg, 1988). Perhaps when a person chews, facial muscles are stimulated in a similar way as when one smokes, which would in turn elicit similar emotions. If the emotions that come with this chewing/smoking muscle activation are positive, it would make sense that this type of stimulation would be reinforcing. Chewing has also been described as a tension outlet that may serve as a technique of relaxation (Hollingworth, 1939). In this study, it was found that "the collateral motor automatism 
involved in the sustained use of the conventional masticatory muscles does result in a lowering of tension." It was mentioned previously that many people smoke in order to avoid or relieve withdrawal symptoms, two of which are closely tied to tension namely, anxiety and restlessness. If chewing serves as a means of reducing tension-related withdrawal symptoms, perhaps the smoker that is reinforced by the alleviation of these withdrawal symptoms would find chewing gum to be an adequate substitute.

There are many other theories as to why chewing gum may serve as an adequate substitute for cigarette smoking. For example, both actions provide social reinforcement, both are conditioned reinforcers, and both have been shown to curb appetites, which help people to maintain their weight. If both activities are reinforcing in similar ways, perhaps the substitution of one commodity for the other is a credible idea. Nevertheless, most gum chewers and cigarette smokers would refrain from giving any reasons for their habits other than the fact that both activities are highly pleasurable.

\section{Goal of Present Study}

The present study was designed to examine the usefulness of the substitution of gum for cigarettes when a dependent smoker is unable to smoke and "craving" a cigarette. As previously mentioned, nicotine can serve as an effective positive reinforcer, and nicotine deprivation can increase the reinforcing effectiveness of cigarettes (Henningfield \& Griffiths, 1979). Extended periods of deprivation are associated with an uncomfortable withdrawal syndrome which makes up another mechanism by which the reinforcing capability of nicotine would be further increased. The drug effect that provides the means for this discomforting withdrawal is physical dependence and several of the symptoms of nicotine withdrawal correspond to the effects of nicotine that are either known or 
suspected to promote tobacco dependence (US DHHS, 1988). Symptoms reported by large numbers of ex-smokers included "craving" for tobacco, anxiety, impatience (Hughes, Gust, \& Pechacek, 1987), restlessness, nervousness, or irritability (Trahir, 1967), difficulty concentrating, increased appetite (Wynder, Kaufman, \& Lesser, 1967), somatic or physical complaints (Pederson \& Lefcoe, 1976), and weight gain (Mausner, 1970).

In comparing the diagnostic criteria for nicotine withdrawal in the DSM-III-R and DSM-IV it can be seen that there are relatively few changes. Six of the eight symptoms listed in the DSM-IV are the same as they were in the DSM-III-R [(1) irritability, frustration, or anger, (2) anxiety, (3) difficulty concentrating, (4) restlessness, (5) decreased heart rate, and (6) increased appetite or weight gain], with "dysphoric or depressed mood," and "insomnia" being added. The other difference is the exclusion of "craving for nicotine" from the DSM-IV, which has been debated. The inclusion of this symptom for nicotine withdrawal but not for most other withdrawal syndromes in the DSM-III-R was taken to imply that craving is more closely tied to withdrawal from nicotine than for other drugs, however there is no data to support this idea (West \& Kranzler, 1992). In addition, it is debatable whether craving during smoking cessation is actually influenced by nicotine administration (Hughes \& Hatsukami, 1985). For example, it is possible for a person to crave nicotine even while smoking and clearly not experiencing withdrawal.

Although these data suggest that craving was justly dropped as a criterion in the DSM-IV, other data suggest the opposite. Craving is one of the most common and reliable effects of tobacco abstinence (Hughes \& Hatsukami, 1986), and it has been shown that craving can be a predictor in relapse (Covey, Glassman, \& Stetner, 1990). Lastly, 
due to the larger variety of environmental cues for smoking compared with other substances of abuse, craving for tobacco may be more prevalent than it is for other drugs of abuse.

Several studies have demonstrated that the symptoms resulting from cigarette deprivation mentioned above are alleviated if the person resumes smoking (Murphee \& Shultz, 1968; Weybrew \& Stark, 1967; Henningfield, 1987). In the present study, it was anticipated that gum chewing would serve as a means of alleviating the signs and symptoms of tobacco withdrawal, especially the "craving" for a cigarette. Because everyone experiencing nicotine withdrawal does not exhibit all of the symptoms listed in the DSM-IV, the hypotheses for this study addressed both specific and general withdrawal symptoms. One hypothesis closely examined the most common and reliable symptom of withdrawal (i.e., craving), whereas the second examined the total withdrawal symptoms experienced. Specifically, if a smoker's craving for a cigarette is decreased by the use of gum, it was also predicted that the use of gum would affect the other symptoms of nicotine withdrawal, thereby serving as a substitute for smoking. These findings would be relevant to the treatment of tobacco dependence, in that it would help to develop better smoking cessation programs, in turn enabling more smokers to overcome their nicotine dependence.

\section{Statement of Hypotheses}

For this study, two specific hypotheses were made, each predicting a significant difference in the severity of the withdrawal symptoms associated with the abstinence of nicotine. 
Hypothesis 1: It was predicted that the subjects who were given access to chewing gum during the time in which they were not permitted to smoke (gum condition) would have significantly lower scores on the cigarette craving item on the Withdrawal Symptom Checklist than subjects not given access to gum during that time (no-gum condition). The null hypothesis stated that there would be no significant difference on the item that is designed to measure craving on the Withdrawal Symptom Checklist between the gum and no-gum groups. The dependent variable for this hypothesis was the reported level of craving (on a 4-point Likert scale of 0 to 3 ), and the independent variable was whether or not the subject was given access to chewing gum.

Hypothesis 2: It was predicted that the total score obtained from the Withdrawal Symptom Checklist would be significantly lower in the gum condition than in the no-gum condition. This would indicate that the total number of withdrawal symptoms experienced by those in the gum condition was significantly less than the withdrawal symptoms experienced by those in the no-gum condition. The null hypothesis stated that there would be no significant difference found on the total score of the Withdrawal Symptom Checklist among the gum and no-gum groups. The dependent variable for this hypothesis was the total score from the Withdrawal Symptom Checklist, and the independent variable was whether or not the subject was given access to chewing gum.

In addition to the two hypotheses listed above, exploratory analyses of each item on the Withdrawal Symptom Checklist was performed in order to develop future hypotheses regarding specific withdrawal symptoms most affected by the use of chewing gum. From these data, preliminary information was derived that addressed when gum 
chewing is an effective substitute for smoking based on one's withdrawal symptoms. These findings are only preliminary however, and need to be replicated in future studies.

\section{Method}

\section{Subjects}

Subjects for this study were 20 dependent cigarette smokers who reported smoking 16 cigarettes or more per day for at least 6 months. Potential participants were excluded if they had inade a serious attempt to quit smoking within the last 6 months, reported heart dysfunction or disease, or were under 18 years of age. Subjects were recruited from psychology courses offered at Oklahoma State University.

\section{Materials}

Tobacco Withdrawal Symptom Checklist (WSC; Hughes \& Hatsukami, 1986). The WSC is a 12-item self-report measure that is designed to assess the presence of tobacco withdrawal symptoms and the severity of each symptom. The severity of each symptom is based on a 4-point Likert scale, ranging from 0 (not present) to 3 (severe). In addition to the 12 items, there is room for respondents to list somatic difficulties (i.e., sweating, nausea) and any changes in behavior (i.e., increase in gum chewing or exercise) since discontinuing their tobacco use.

\section{Procedure}

This study will serve as the creative component for the degree of Master of Science at Oklahoma State University and assessed the effect that chewing gum has on withdrawal symptoms in dependent cigarette smokers. At the beginning of each session, all participants were asked to smoke a cigarette and then rate their current withdrawal symptoms by completing the WSC (Baseline). Subjects were then asked to watch a movie 
that they themselves had picked from a large library of movies. During the course of the movie, subjects did not have access to cigarettes. Upon completion of the movie, subjects were again asked to complete the WSC (Time 1). Subjects were then asked to remain in the lab for approximately 30 minutes. During this time, subjects continued to have no access to cigarettes. Finally, all the subjects completed the WSC one last time (Time 2). Half of the subjects run in this study were asked to chew gum during the time in which he/she was denied access to cigarettes. Subjects were assigned randomly to gum or nogum groups.

\section{Results}

\section{Design}

Three measures of tobacco withdrawal were obtained for each subject. The first measure (Baseline) was taken after each subject smoked a standard cigarette. This measure was to taken prior to the movie, and was used to determine the subject's baseline level of withdrawal. The second measure (Time 1) was taken upon termination of the movie, and the third measure (Time 2) was taken 30 minutes later. The analytic strategy was to use baseline scores as a covariate if there were observed differences between groups on this measure. With one exception, no differences were observed on the baseline measure, thus baseline scores were not entered as the covariate except for in the case of the exception ("Drowsiness"). These results are summarized in Table 1.

Insert Table 1 about here 
The data were analyzed using a 2 X 2 (Gum Condition vs. No Gum Condition X Time) repeated measures analysis of variance (ANOVA), with Time being the repeated measure (Time 1 and Time 2). For the symptom drowsiness, because there was a significant difference observed between groups at Baseline $[t(18)=2.86, p=.01]$, a $2 \times 2$ (Gum Condition vs. No Gum Condition X Time) repeated measures analysis of covariance (ANCOVA) with Time being the repeated measure (Time 1 and Time 2) was used. Baseline drowsiness was used as the covariate to correct for the significant difference observed between the gum and no-gum conditions prior to the movie.

\section{Hypothesis 1}

Means for the "craving" item on the Withdrawal Symptom Checklist (WSC) at Time 1 and Time 2 are presented in Figure 1 and the results from these analyses are summarized in Table 2. For this hypothesis, craving served as the dependent measure. As hypothesized, a significant Condition by Time interaction was observed, $\underline{F}(1,18)=13.36$, p $<.01$. To further analyze the observed Condition $X$ Time interaction post hoc analyses were used. A significant difference in craving was not observed at Time $1[\underline{F}(1,18)=0.21$, n.s.], but was observed at Time $2[\underline{F}(1,18)=38.04, \underline{p}<.01]$.

Insert Figure 1 and Table 2 about here

\section{Hypothesis 2}

Means for the total score obtained from the WSC at Time 1 and Time 2 are presented in Figure 2 and the results from these analyses are summarized in Table 3. For this hypothesis, the total score obtained from the WSC was the dependent measure. 
Total score was obtained by taking the sum of all the items listed on the WSC. Again, as hypothesized a significant Condition by Time interaction was observed, $\underline{F}(1,18)=6.08$, $\mathrm{p}<.05$. To further analyze this observed Condition X Time interaction post hoc analyses were also used. Significant differences in the total WSC scores were observed at both Time $1[\underline{\mathrm{F}}(1,18)=7.90, \underline{\mathrm{p}}<.05]$, and Time $2[\underline{\mathrm{F}}(1,18)=37.25, \underline{\mathrm{p}}<.01]$.

Insert Figure 2 and Table 3 about here

\section{Exploratory Analyses}

In addition to the above analyses, exploratory analyses were performed on each item on the WSC. This was done so that hypotheses regarding the specific withdrawal symptoms most affected by the use of chewing gum can be developed in the future. The results from the exploratory analyses are summarized in Table 3 and the means for Time 1 and Time 2 for the remaining withdrawal symptoms listed on the WSC are presented in Figures 3-13. Of note is the significant Condition $X$ Time interaction for the symptom "Restlessness" $[\underline{F}(1,18)=4.80, \underline{p}<.05]$. Also, significant differences found in the factor Time for "Difficulty Concentrating" $[\underline{F}(1,18)=10.57, \underline{\underline{p}}<.01]$, "Fatigue" $[\underline{F}(1,18)=6.08$, $\underline{p}<.05]$, "Impatience" $[\underline{F}(1,18)=8.73, \underline{p}<.01]$, and "Irritability" $[\underline{F}(1,18)=7.51, \underline{p}<.05]$ were observed. A significant main effect for Condition on the "Fatigue" item was observed as well $[\underline{\mathrm{F}}(1,17)=5.58, \underline{\mathrm{p}}<.05]$.

Some unusual results are also noteworthy. For the symptom "Headache", $\underline{F}$ 's for the within-subjects variables (Time and Condition X Time) were identical, due to the fact that there was no variance observed the scores obtained from those in the Gum Condition. 
In fact, upon reviewing the raw data it was observed that only three subjects in the Gum Condition reported a headache at either of the times in which the measures were taken and at both times the reported intensity of the headache was the same. Similarly for the symptom, "Intestinal Disturbance," F's for the within-subjects variables were also identical since there was very little variance observed in the Gum Condition. Upon reviewing the raw data for this symptom, it was observed that only one subject in the Gum Condition reported intestinal disturbance and this report was only at Time 2 .

Lastly, for the symptom, "Insomnia", F's were not computed due to the fact that there was again no variance in the scores since no subject reported having insomnia. This makes sense given that the subjects in this study were not asked to sleep during the time they were in the lab. Because no one attempted to sleep, it could not be determined if insomnia was experienced.

Insert Table 4 and Figures 3-13 about here

\section{Discussion}

The results of this study suggest that chewing gum reduces craving and helps with withdrawal when a nicotine dependent person cannot smoke. The results do not suggest however, that chewing gum will allow a person to avoid withdrawal altogether. Withdrawal was clearly seen in all the subjects who participated in this study, yet it was observed less acutely in subjects that were asked to chew gum. Interestingly, the "craving" that smokers often report having for a cigarette when their blood nicotine levels 
drop, appeared to decrease if they were given access to chewing gum during the time in which they were asked to withhold from smoking. This drop in craving however, was small.

Hypotheses predicted that dependent smokers who had access to chewing gum would not only experience less craving for a cigarette, but would also experience less withdrawal on the whole. In this study, a "real world" situation was simulated in order to test these hypotheses. In the "real world" when a person goes out to watch a movie, he/she is usually banned from smoking inside the theater. Typically after viewing a movie, a dependent smoker will leave the theater and smoke a cigarette. In the present study, this response was prevented by having the smoker remain in the lab for 30 minutes after the movie had concluded. As expected, the results were in accord with both hypotheses. For Hypothesis 1, it was predicted that subjects in the Gum Condition would have significantly lower scores on the item measuring craving on the WSC, and this was observed. Similarly, for Hypothesis 2 it was predicted that the total score obtained from the WSC would be significantly lower in the Gum Condition, and again, this was confirmed.

There were interesting findings based on the exploratory analyses that were performed as well. The exploratory analyses examined each of the remaining withdrawal symptoms found on the WSC. Although a significant reduction in both craving and total withdrawal was observed in the Gum Condition, when the individual symptoms were examined the results were not as clean cut. The only other symptom that was shown to have a significant reduction was restlessness, and again the reduction observed was in the Gum Condition. This finding makes sense since two of the major reasons that people 
chew gum is to get relief from tension by discharging nervous energy, and to provide a quick, socially acceptable outlet for anger and irritation (Hendrickson, 1976).

Interestingly, no other individual symptom showed a significant reduction in ether the Gum or No Gum Conditions. This is not all that surprising given that everyone who experiences nicotine withdrawal will not exhibit all of the symptoms listed in the DSM-IV. Thus, because nicotine withdrawal is different for different people, it makes sense that even though a significant reduction in total withdrawal was observed there was no significant reduction observed in most of the individual symptoms when they were examined by themselves.

These findings suggest that chewing gum may be an adequate substitute for cigarettes when cigarettes are unavailable to a smoker. There are several explanations that may account for this finding, however according to Hursh and Bauman (1987) commodities are more likely to be substitutes when they share similar properties and effects. Because both chewing gum and cigarettes are administered orally, require movement of the jaw muscle, and offer stimulant effects, it is clear that this type of relationship between the two commodities is plausible.

There are some apparent clinical implications that that are hinted at based on the findings of this study. Because craving is one of the most common and reliable effects of tobacco abstinence (Hughes \& Hatsukami, 1986), and it has been shown that craving can be a predictor in relapse (Covey, Glassman, \& Stetner, 1990) it seems only fitting that smoking cessation programs target this symptom. This study suggested that smokers who chew gum when they do not have access to cigarettes report significantly less craving than smokers who do not chew gum. In fact, as time went on, the amount of craving that was 
reported by those that chewed gum lessened whereas those that did not chew gum actually reported an increase in craving.

In addition, although all subjects in this study clearly experienced nicotine withdrawal, it appears that chewing gum helps with total withdrawal. This statement should not be misunderstood as stating that chewing gum will get rid of withdrawal, but perhaps when a smoker finds him/herself in a situation where withdrawal is greater than usual a stick of chewing gum may help to bring the withdrawal symptomology back down to more tolerable levels.

\section{Limitations}

Although the present study showed that chewing gum seems to lessen craving and helps with nicotine withdrawal when a person cannot smoke, it tells us little about whether gum can reduce smoking when cigarettes are available to a person. In order to determine if chewing gum is a true substitute for cigarettes, a related study has recently been undertaken where subjects will have free access to cigarettes throughout the study. Half the subjects who chose to participate in this study will be given access to chewing gum while the other half will not, and small rewards (i.e., McDonalds food coupons) will be offered to those who do not smoke. If chewing gum is indeed a substitute for cigarettes, those smokers that are given access to gum should be more successful in abstaining than the smokers who will not have access to gum.

Finally, another limitation of the present study is that the smokers who participated in this study were not actually trying to quit smoking, rather they were asked only to refrain from smoking for approximately 3 hours. Perhaps the results that were found in this study apply only to smokers who find themselves in situations where they are unable 
to smoke (i.e., in a movie theater, at work), and do not apply to smokers who wish to quit. Future research must address this question to see if there is a difference in those who are abstaining and those who wish to stop smoking for good. 


\section{References}

Allison, J. (1979). Demand economics and experimental psychology. Behavioral Science, $24,403-415$.

Bickel, W. K., DeGrandpre, R. J., Hughes, J. R., \& Higgins, S. T. (1991).

Behavioral economics of drug self-administration: II. A unit-price analysis of cigarette smoking. Journal of the Experimental Analysis of Behavior, 55, 145-154.

Bickel, W. K., Hughes, J. R., DeGrandpre, R. J., Higgins, S. T., \& Rizzuto, P. (1992). Behavioral economics of drug self-administration: IV. The effects of response requirement on the consumption of and interaction between concurrently available coffee and cigarettes. Psychopharmacology, 107, 211-216.

Covey, L.S., Glassman, A. H., \& Stetner, F. (1990). Depression and depressive symptoms in smoking cessation. Comparative Psychiatry, 31, 350-354.

DeGrandpre, R.J., Bickel, W. K., Hughes, J. R., \& Higgins, S. T. (1992). Behavioral economics of drug-self-administration: III. A reanalysis of the nicotine regulation hypothesis. Psychopharmacology $108,1-10$.

Dimberg, U. (1988). Facial electromyography and the experience of emotion. Journal of Psychophysiology $2 \underset{2}{2}$ 277-282.

Epstein, L. H. \& Jennings, J. R. (1986). Smoking, stress, cardiovascular reactivity, and coronary heart disease. In K. A. Matthews, S. M. Weiss, T. Detre, T. M. Dembroski, B. Falkner, S. B. Manuck, \& R. B. Williams Jr. (Eds.), Handbook of stress, reactivity, and cardiovascular disease. New York: John Wiley \& Sons. 
Griffiths, R. R., Bigelow, G. E., \& Liebson, I. (1976). Facilitation of human tobacco self-administration by ethanol: A behavioral analysis. Journal of the Experimental Analysis of Behavior, 25, 279-292.

Hendrickson, R. (1976). The Great American Chewing Gum Book. Radnor, PA: Chilton Book Company.

Henningfield, J. E., \& Griffiths, R. R. (1979). A preparation for the experimental and analysis of human cigarette smoking behavior. Behavior Research Methods Instrumentation, 11, 538-544.

Henningfield, J. E. (1987). Annual Progress Report: Biology of Dependence and Abuse Potential Assessment Laboratory. In: Annual Report of the Addiction Research Center, Addiction Research Center, National Institute on Drug Abuse.

Hollingworth, H. L. (1939). Chewing as a technique of relaxation. Science, 90. 385-387.

Hughes, J. R., Gust, S. W., \& Pechacek, T.F. (1987). Prevalence of tobacco dependence and withdrawal. The American Journal of Psychiatry, 144, 205-208.

Hughes, J. R. \& Hatsukami, D. K. (1985). Short-term effects of nicotine gum. In J. Grabowski \& S. Hall (Eds.), Pharmacological Adjuncts in Smoking Cessation. (NIDA Research Monograph No 53) (DHHS Publication No. ADM-85-1333). Washington, DC: U.S. Government Printing Office.

Hughes, J. R. \& Hatsukami, D. K. (1986). Signs and symptoms of tobacco withdrawal. Archives of General Psychiatry, 43, 289-294.

Hursh, S.R. (1984). Behavioral economics. Journal of the Experimental Analysis of Behavior, 42, 435-452. 
Hursh, S. R., \& Bauman, R. A. (1987). The behavioral analysis of demand. In L. Green \& J. H. Kagel (Eds.), Advances in behavioral economics (Vol. 1, pp. 117-165). Norwood, NJ: Ablex.

Hursh, S. R., Raslear, D., Shurtleff, R., Bauman, R., \& Simmons, L. (1988). A cost benefit analysis of demand for food. Journal of the Experimental Analysis of Behavior, 50 419-440.

Kessler, D. A. (Commissioner of Food and Drugs). (1994, March 25). Statement on nicotine-containing cigarettes, Statement delivered to the House Subcommittee on Health and the Environment.

Lichtenstein, E. \& Glasgow, R. (1992). Smoking cessation: What have we learned over the past decade? Journal of Consulting and Clinical Psychology 60 518527.

Marshall, W. R., Epstein, L. H., \& Green, S. B. (1980). Coffee drinking and cigarette smoking: I. Coffee, caffeine, and cigarette smoking behavior. Addictive Behaviors, $5,389-394$.

Marshall, W. R., Green, S. B., Epstein, L. H., Rogers, C. M., \& McCoy, J. F. (1980). Coffee drinking and cigarette smoking: II. Coffee, urinary pH and cigarette smoking behavior. Addictive Behaviors, $5,395-400$.

Mausner, J. S. (1970). Cigarette smoking among patients with respiratory disease. American Review of Respiratory Disease, 102, 704-713.

Murphee, H. B., \& Schultz, R. E. (1968). Abstinence effects in smokers. (Abstract.) Federal Proceedings, 27, 220. 
National Institute on Drug Abuse. (1994). National survey results on drug use from monitoring the future study, 1975-1993. Volume II: College students and young adults (NIH Publication No. 94-3810). Washington, DC: U.S. Government Printing Office.

Pederson, L. L., \& Lefcoe, N. M. (1976). A psychological and behavioural comparison of ex-smokers and smokers. Journal of Chronic Diseases, 29, 431-434.

Perkins, K. A., Epstein, L. H., Sexton, J. E., \& Pastor, S. (1990). Effects of smoking cessation on consumption of alcohol and sweet, high-fat foods. Journal of Substance Abuse, 2 , 287-297.

Schacter, S., Silverstein, B., Kozlowski, L., Perlick, D., Herman, C., \& Liebling, B. (1977). Studies of the interaction of psychological and pharmacological determinants of smoking. Journal of Experimental Psychology: General, 106, 3-40.

Trahir, R. C. S. (1967). Giving up cigarettes: 222 case studies. Medical Journal of Australia, 1, 929-932.

U.S. Department of Health and Human Services. (1990). Smoking and Health: A National Status Report (DHHS Publication No. CDC 87-8396). Washington, DC: Government Printing Office.

U.S. Department of Health and Human Services. (1988). The Health Consequences of Smoking: Nicotine Addiction (DHHS Publication No. CDC 88-8406). Washington DC: Government Printing Office.

West, R. J., \& Kranzler, H. R. (1992). Craving for cigarettes and psychoactive drugs. In D. Warburton (Ed.), Addiction Controversies. New York: Harwood Academic Publishers. 
Weybrew, B. B., \& Stark, J. E. (1967). Psychological and Physiological Changes Associated with Deprivation from Smoking. U.S. Naval Submarine Medical Center Report No. 490. Bureau of Medicine and Surgery, Navy Department.

Wynder, E. L., Kaufman, P. L., \& Lesser, R. L. (1967). A short-term follow up study on ex-cigarette smokers. American Review of Respiratory Disease, 96, 645-655. 
Appendix

\section{Tobacco Withdrawal Symptom Checklist}

Directions: Please rate (circle) the level of your current withdrawal symptoms.

\section{NOT PRESENT MILD MODERATE SEVERE}

1. Craving

2. Irritability

3. Anxiety

4. Difficulty Concentrating

5. Restlessness

6. Headache

7. Drowsiness

8. Intestinal Disturbance

9. Fatigue

10. Impatience

11. Hunger

12. Insomnia
0

0

0

0

0

0

0

0

0

0

0

0

\section{1}

1

1

1

1

1

1

1

1

1

1

1
2

2

2

2

2

2

2

2

2

23

Please list any somatic (bodily) difficulties you are currently experiencing (i.e. sweating, dizziness, nausea).

1.

3.

Have you noticed any changes since your last cigarette?

If yes, what have you noticed?
2

4.

Yes

No 
Table 1

t-tests for Differences Between Condition at Baseline

Preliminary Analyses

\begin{tabular}{lccc} 
& t-value & df & Sig. \\
\hline Craving & -1.20 & 18 & .246 \\
Total Withdrawal Symptoms & .88 & 18 & .389
\end{tabular}

\section{Exploratory Analyses}

t-value

.00

Anxiety

Difficulty Concentrating

Drowsiness

Fatigue

Headache

Hunger

Intestinal Disturbance

Impatience

Insomnia

Irritability

Restlessness
$-.34$

2.86

1.70

.00

.37

1.96

$-.23$

1.41

1.10

18

18

.00

18
Sig.

1.000

.736

$.010^{*}$

.106

1.000

.714

.065

.818

.177

.288

1.000 
Table 2

Craving

Initial Analyses

Source

SS

df

MS

F

p

Between-subjects

Error 20.45

3.02

18

1.14

3.02

2.66

120

Within-subjects

Error

1.65

.63

Time

1.22

18

.09

Condition X Time

.63

1.22

6.82

13.36

$.018^{*}$

$.002 *$

Post Hoc/Simple Effects Test

Source

Craving at Time 1

Error

Condition
1.65

.019
SS

df

18

1
.09

.019

0.21

n.s.

Craving at Time 2

$\begin{array}{lrrrrr}\text { Error } & 1.65 & 18 & .09 & & \\ \text { Condition } & 3.42 & 1 & 3.42 & 38.04 & \mathrm{p}<.01 \text { * }\end{array}$


Table 3

Total Withdrawal Symptoms

Initial Analyses

Source SS

df

MS

F $\quad$ p

Between-subjects

Error

Condition

1058.45
87.03

18

58.80

87.03

1.48

.239

Within-subjects

\begin{tabular}{lrrrrr}
\hline Error & 62.25 & 18 & 3.46 & & \\
Time & 81.22 & 1 & 81.22 & 23.49 & .00 * $^{*}$ \\
Condition X Time & 21.02 & 1 & 21.02 & 6.08 & $.024 *$
\end{tabular}

Post Hoc/Simple Effects Test

$\begin{array}{llllll}\text { Source } & \text { SS } & \text { df } & \text { MS } & \text { F } & \text { p }\end{array}$

Total Withdrawal Symptoms at Time 1

$\begin{array}{lrrrrr}\text { Error } & 21.02 & 18 & 3.46 & & \\ \text { Condition } & 27.34 & 1 & 27.34 & 7.90 & \mathrm{p}<.05^{*}\end{array}$

Total Withdrawal Symptoms at Time 2

$\begin{array}{lrrrrr}\text { Error } & 21.02 & 18 & 3.46 & & \\ \text { Condition } & 128.89 & 1 & 128.89 & 37.25 & \mathrm{p}<.01^{*}\end{array}$


Table 4

Exploratory Analyses

\section{Anxiety}

Source

SS

df

MS

F

Between-subjects

Error

Condition

41.30
10

18

2.29

10

1

.10

.04

.837

Within-subjects

Error

3.70

Time

.90

18

.21

$1 \quad .90$

4.38

.051

Condition X Time

.40

.40

1.95

.180

\section{Difficulty Concentrating}

Source

Between-subjects

Error

Condition

32.85
2.02

Time

Condition X Time

Within-subjects
3.45

2.03

SS

.03 df

18

1

18

1

MS

1.82

2.02

1.11

.306

Condition X Time
.19

.03
F p
$.004^{*}$

.722

\section{Drowsiness}

Source

Between-subjects

Error

Condition
SS

\subsection{6}

1.14

12.50

.40

.10
40

df

17

1

Within-subjects

Error

Time

Condition X Time
18

1

1
MS

F

10.57

.13 
Table 4 (Continued)

\section{Fatigue}

Source

SS

df

MS

F

Between-subjects

Error

28.25

3.02

18

1.57

Condition

$1 \quad 3.02$

1.93

.182

Within-subjects

\begin{tabular}{lrrrrr}
\hline Error & 1.85 & 18 & .10 & & \\
Time & .63 & 1 & .63 & 6.08 & $.024 *$ \\
Condition X Time & .03 & 1 & .03 & .24 & .628
\end{tabular}

\section{Headache}

Source

SS

df

MS

F

Between-subjects

Error

7.40

18

.41

Condition

.00

1

.00

.00

1.000

Within-subjects

$\begin{array}{lrrrrr}\text { Error } & 2.20 & 18 & .12 & & \\ \text { Time } & .40 & 1 & .40 & 3.27 & .087 \\ \text { Condition X Time } & .40 & 1 & .40 & 3.27 & .087\end{array}$

\section{Hunger}

Source

SS

df

MS

F

$p$

Between-subjects

Error

33.50

18

1.86

Condition

.40

1

.40

.21

.648

Within-subjects

Error

5.50

.40

Time

.10

18

31

40

.10

1.31

.268

Condition X Time

1

.33

.574 
Table 4 (Continued)

Intestinal Disturbance

Source $\quad S$

Between-subjects

Error $\quad .4$

Condition

.03

18

03

$1 \quad .03$

1.00

Within-subjects

Error $\quad .4$

Time $\quad .03$

Condition X Time $\quad .03$

$\begin{array}{rr}18 & .03 \\ 1 & .03 \\ 1 & .03\end{array}$

1.00

$.03 \quad 1.00$

.331

Impatience

Source

Between-subjects

Error

Condition
SS

39.30

1.60

18

2.18

1.60

.73

.403

Within-subjects

Error 3.30

Time 1.60

Condition X Time

18

1

.18

1.60

.10

8.73

$.008^{*}$

.55

.470

\section{Insomnia}

Source

Between-subjects

Error

Condition

Within-subjects

Error $\quad .00$

Time

.00

Condition X Time $\quad .00$

.00

SS

df

18

$1 \quad .00$

.00

00
MS

F p

.00

.00

.00 
Table 4 (Continued)

$\underline{\text { Irritability }}$

Source

Between-subjects

Error

Condition

16.65

.23

7.25

3.03

Time

1.23

SS

Condition X Time

Within-subjects

Error

23

df

MS

18

.92

.23

.24

.628

\section{Restlessness}

Source

Between-subjects

Error

Condition

Within-subjects

Error

Time

Condition X Time
SS

36.70

6.40

1.50

.10

.40
18

$1 \quad 3.03$

$1 \quad 1.23$
.40

$\begin{array}{ll}.40 & 7.51\end{array}$

3.04

.098 
Figure Captions

Figure 1. Mean Craving Score for Gum and No Gum Conditions at Time 1 and Time 2.

Figure 2. Mean Total Withdrawal Score for Gum and No Gum Conditions at Time 1 and Time 2.

Figure 3. Mean Anxiety Score for Gum and No Gum Conditions at Time 1 and Time 2

Figure 4. Mean Difficulty Concentrating Score for Gum and No Gum Conditions at Time 1 and Time 2.

Figure 5. Mean Drowsiness Score for Gum and No Gum Conditions at Time 1 and Time 2.

Figure 6. Mean Fatigue Score for Gum and No Gum Conditions at Time 1 and Time 2.

Figure 7. Mean Headache Score for Gum and No Gum Conditions at Time 1 and Time 2.

Figure 8. Mean Hunger Score for Gum and No Gum Conditions at Time 1 and Time 2.

Figure 9. Mean Intestinal Disturbance Score for Gum and No Gum Conditions at Time 1 and Time 2.

Figure 10. Mean Impatience Score for Gum and No Gum Conditions at Time 1 and Time 2 .

Figure 11. Mean Insomnia Score for Gum and No Gum Conditions at Time 1 and Time 2. Figure 12. Mean Irritability Score for Gum and No Gum Conditions at Time 1 and Time 2.

Figure 13. Mean Restlessness Score for Gum and No Gum Conditions at Time 1 and Time 2 . 


\section{Figure 1 \\ Craving}

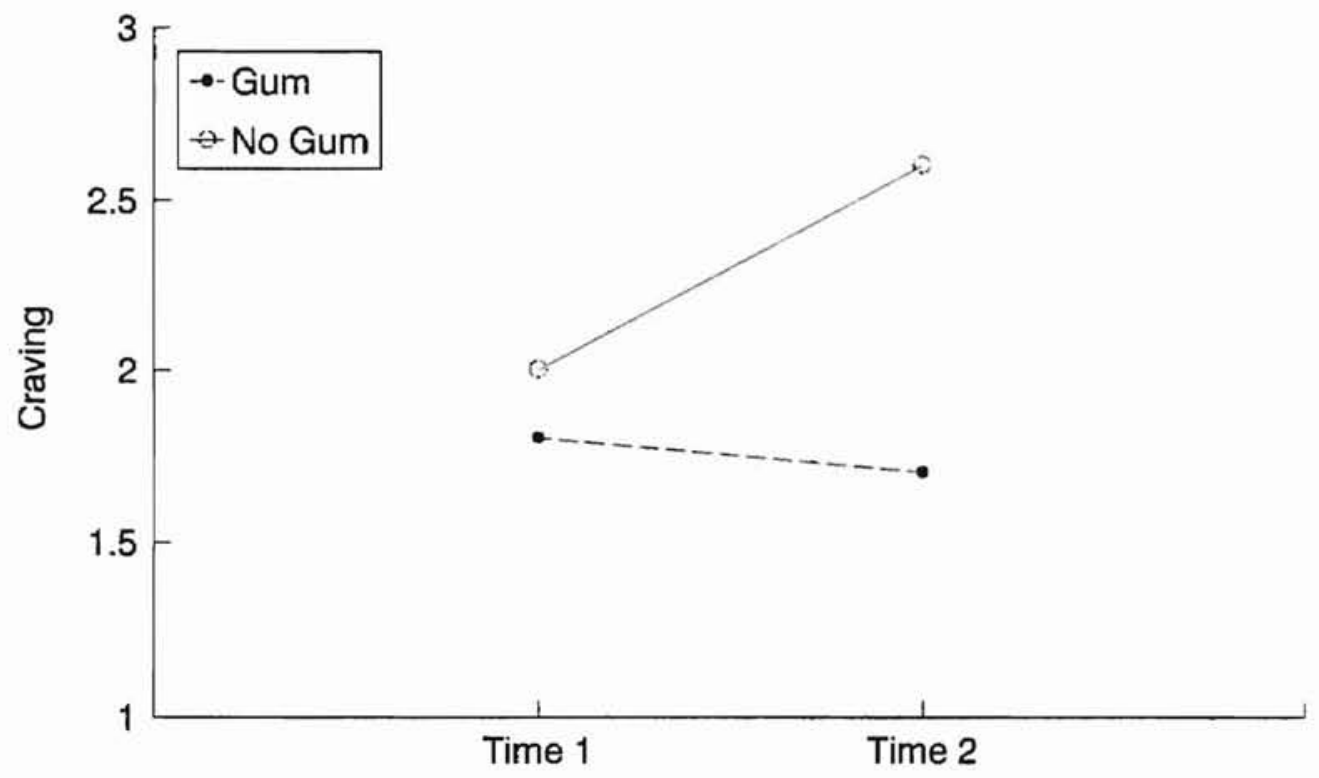

\section{Figure 2 \\ Total Withdrawal Symptoms}

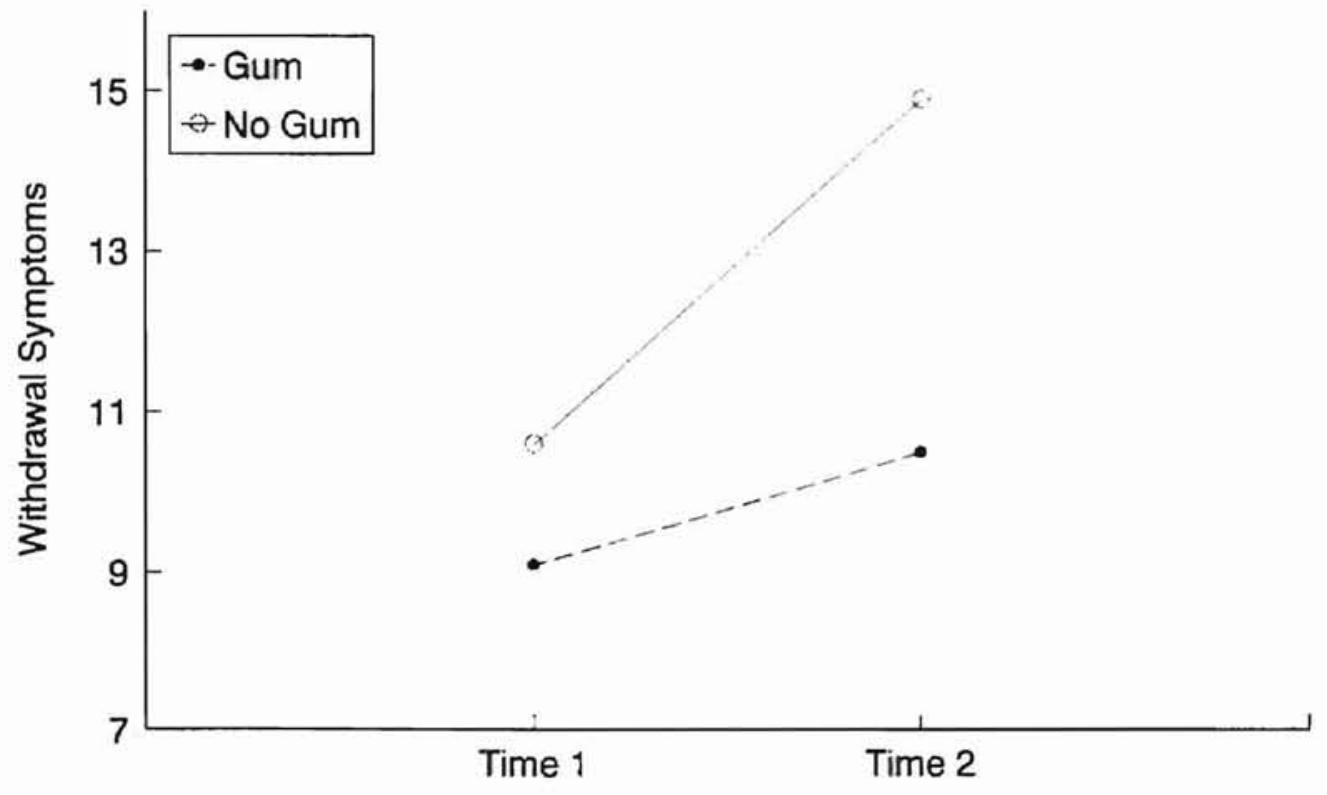


Figure 3

Anxiety

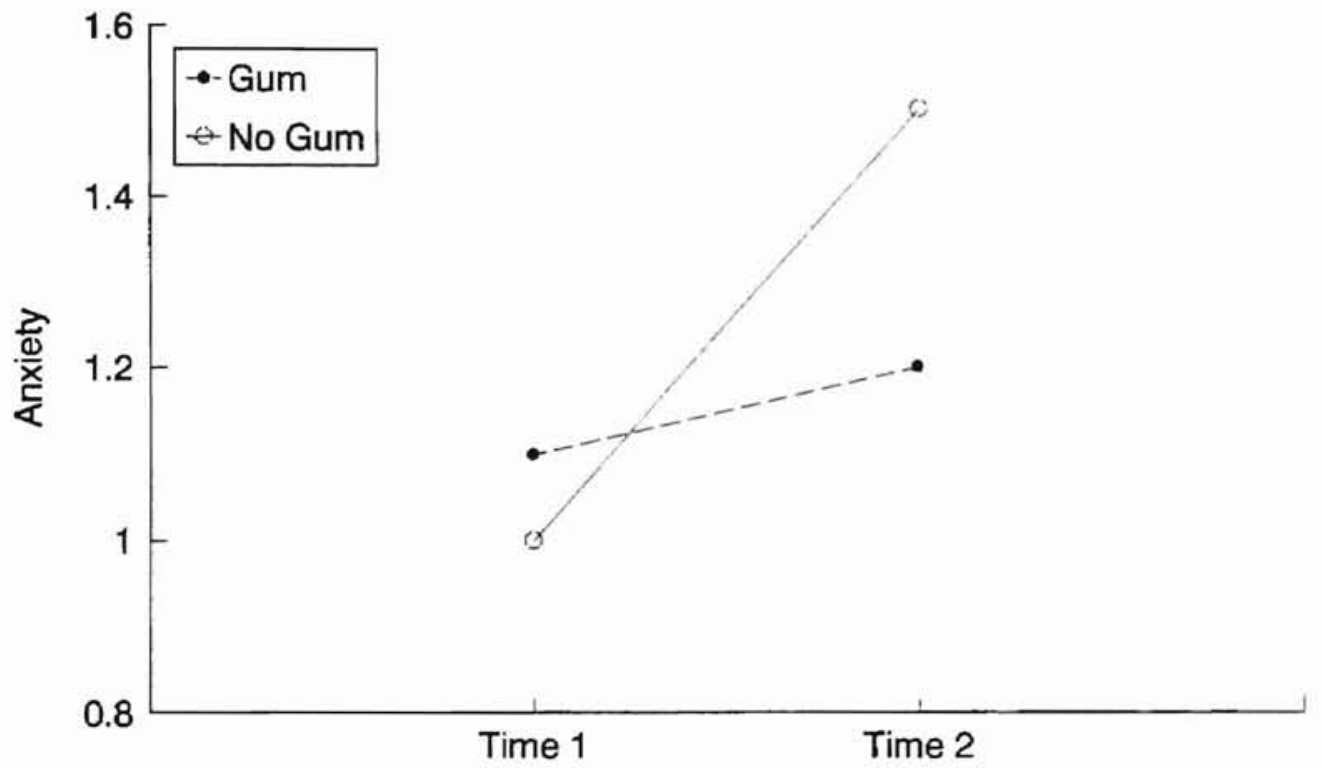

\section{Figure 4}

Difficulty Concentrating

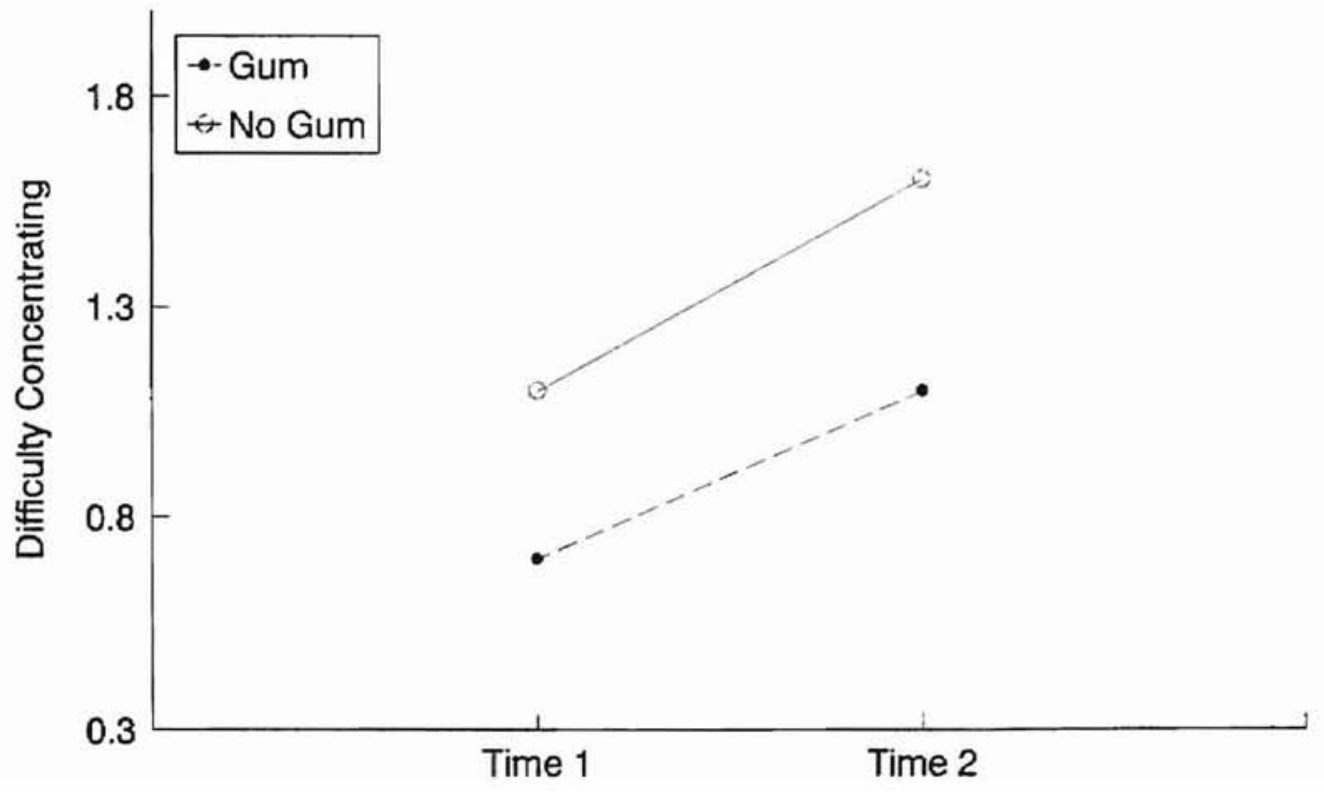




\section{Figure 5}

\section{Drowsiness}
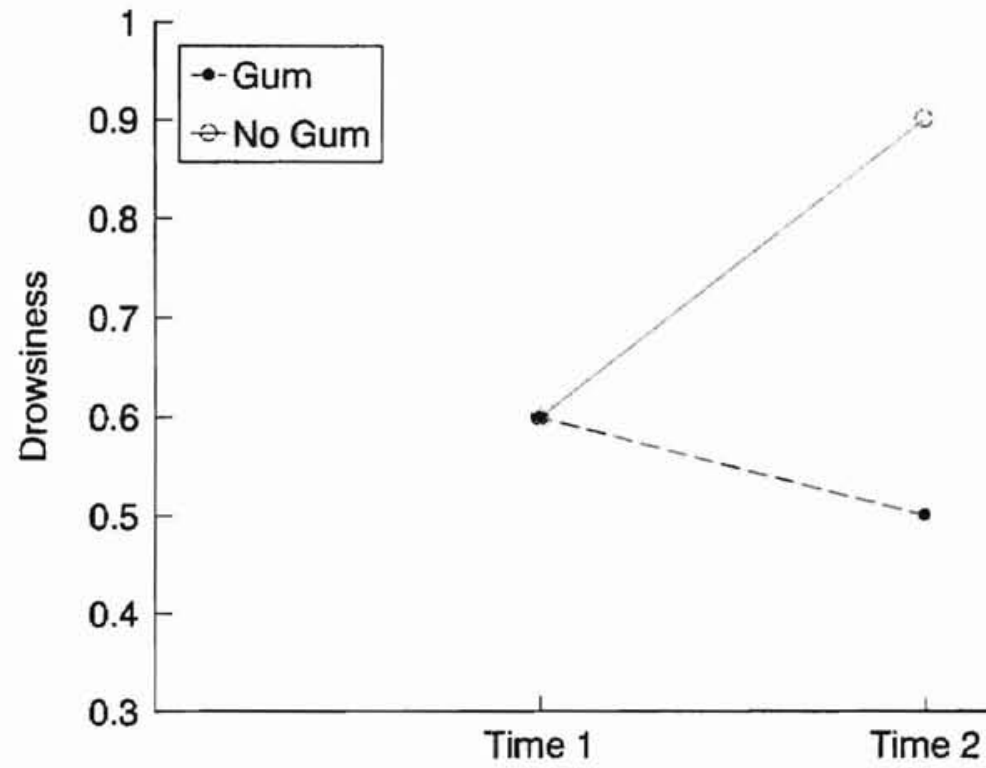

Figure 6

Fatigue

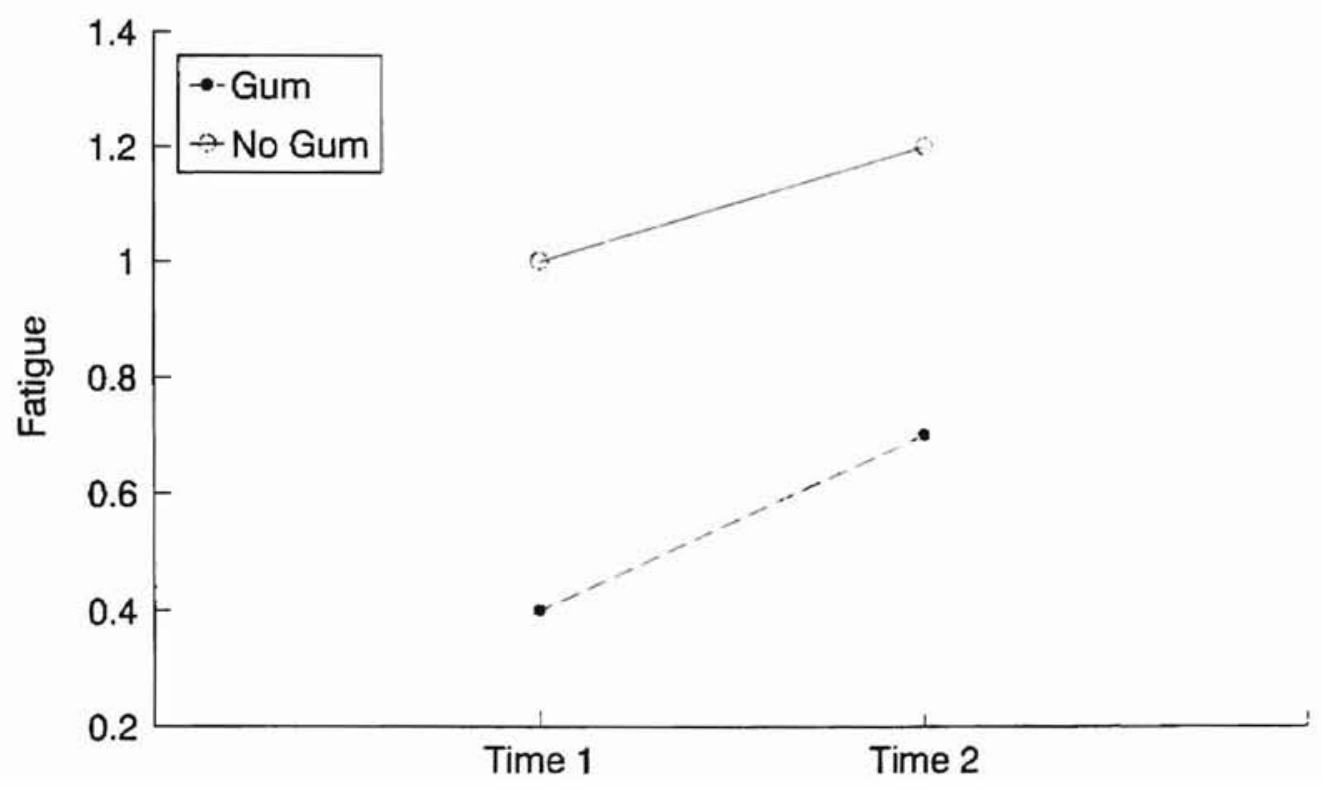




\section{Figure 7}

Headache

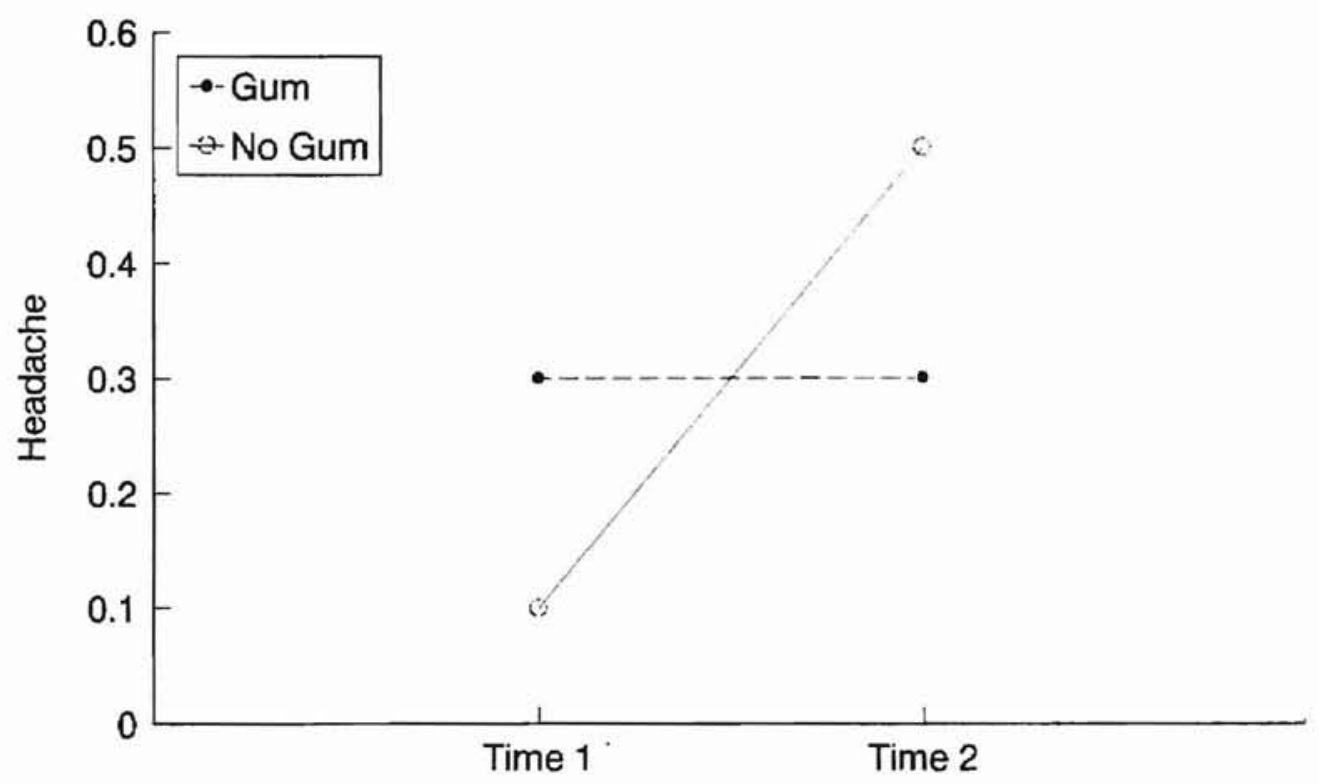

Figure 8

Hunger

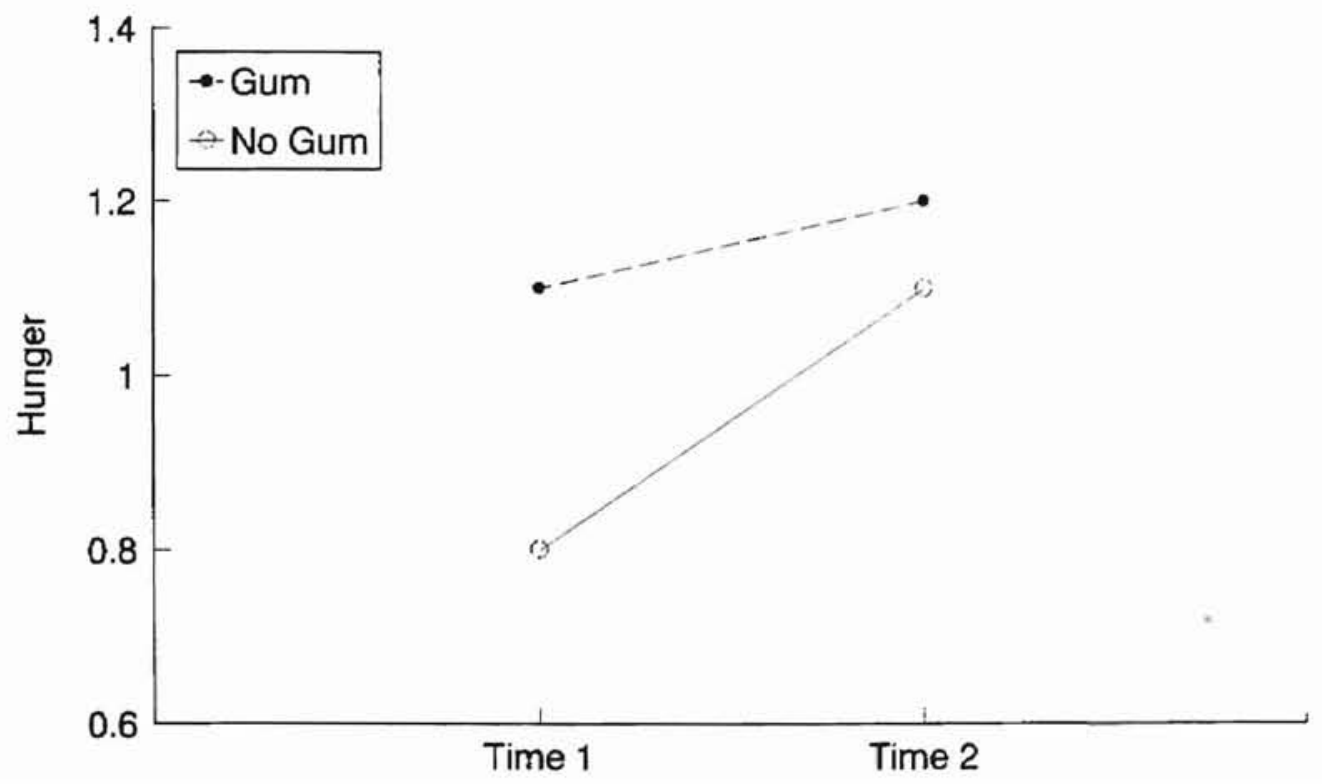




\section{Figure 9 \\ Intestinal Disturbance}

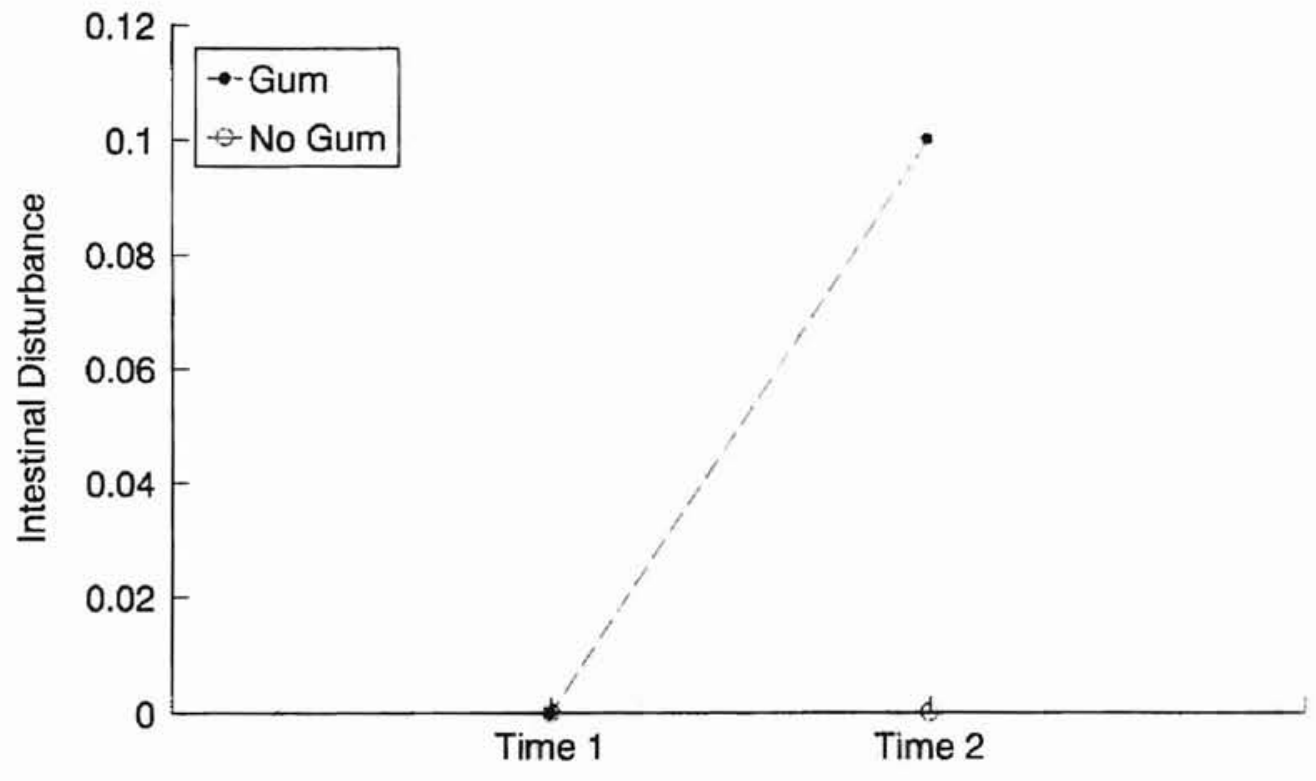

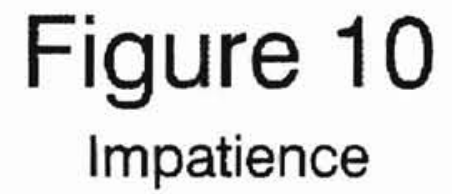

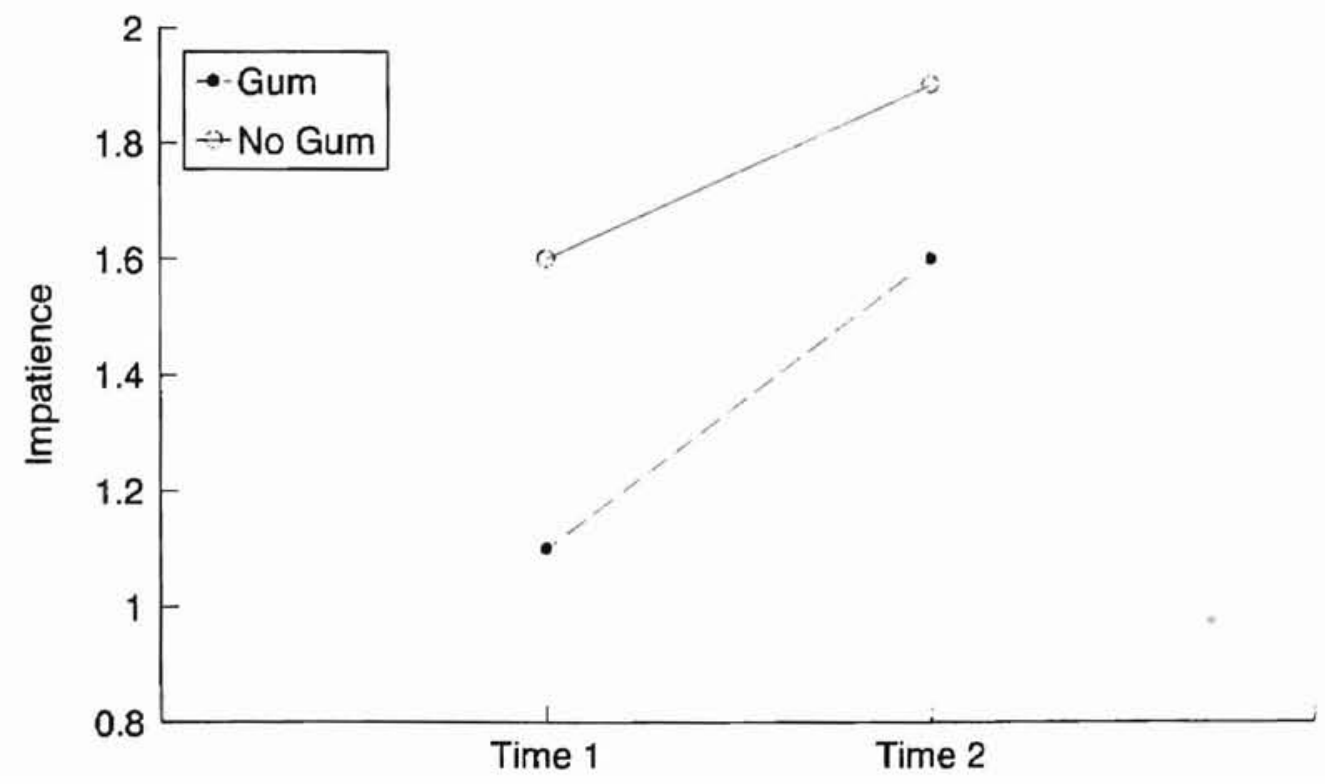


Figure 11

Insomnia
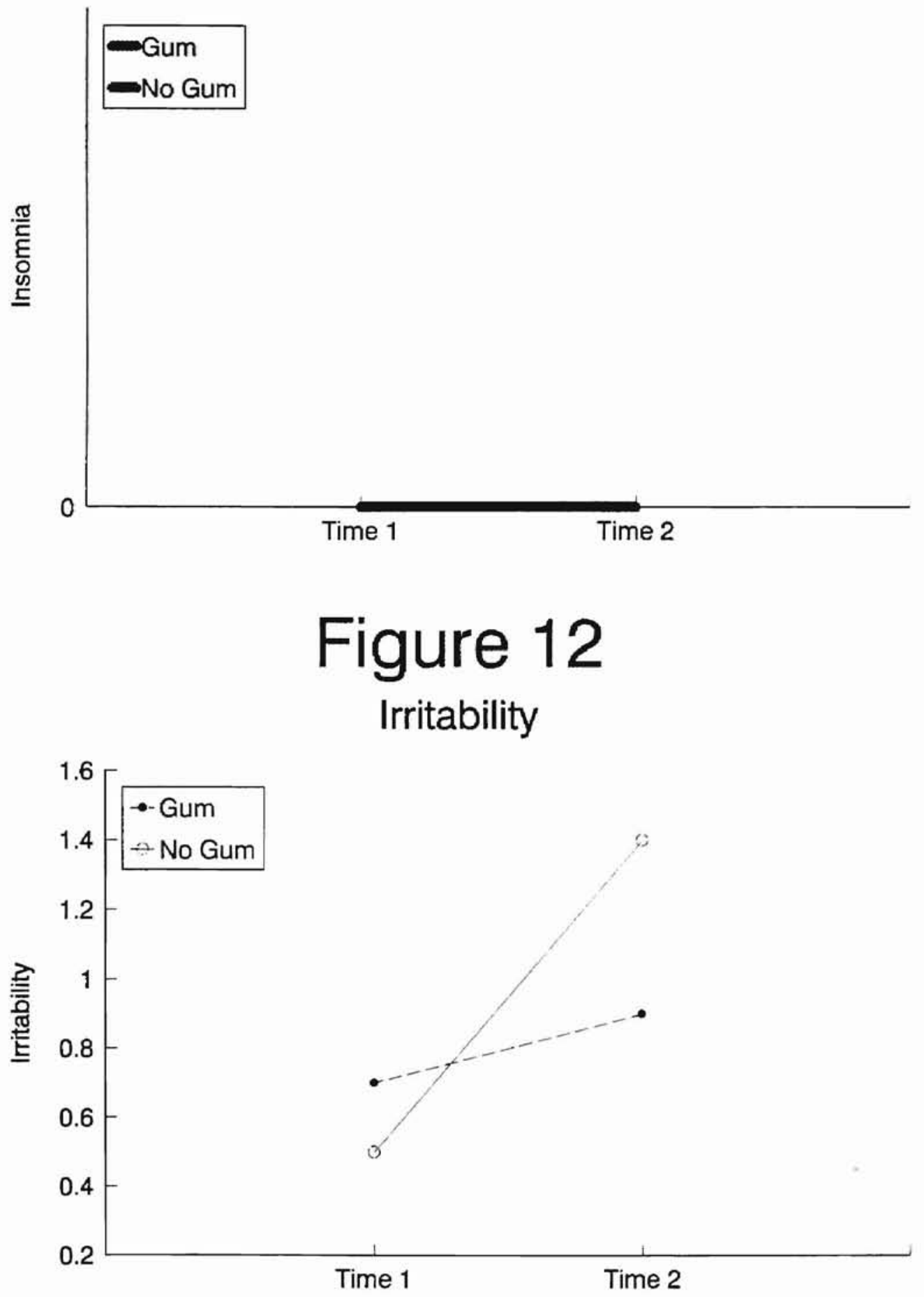


\section{Figure 13 Restlessness}

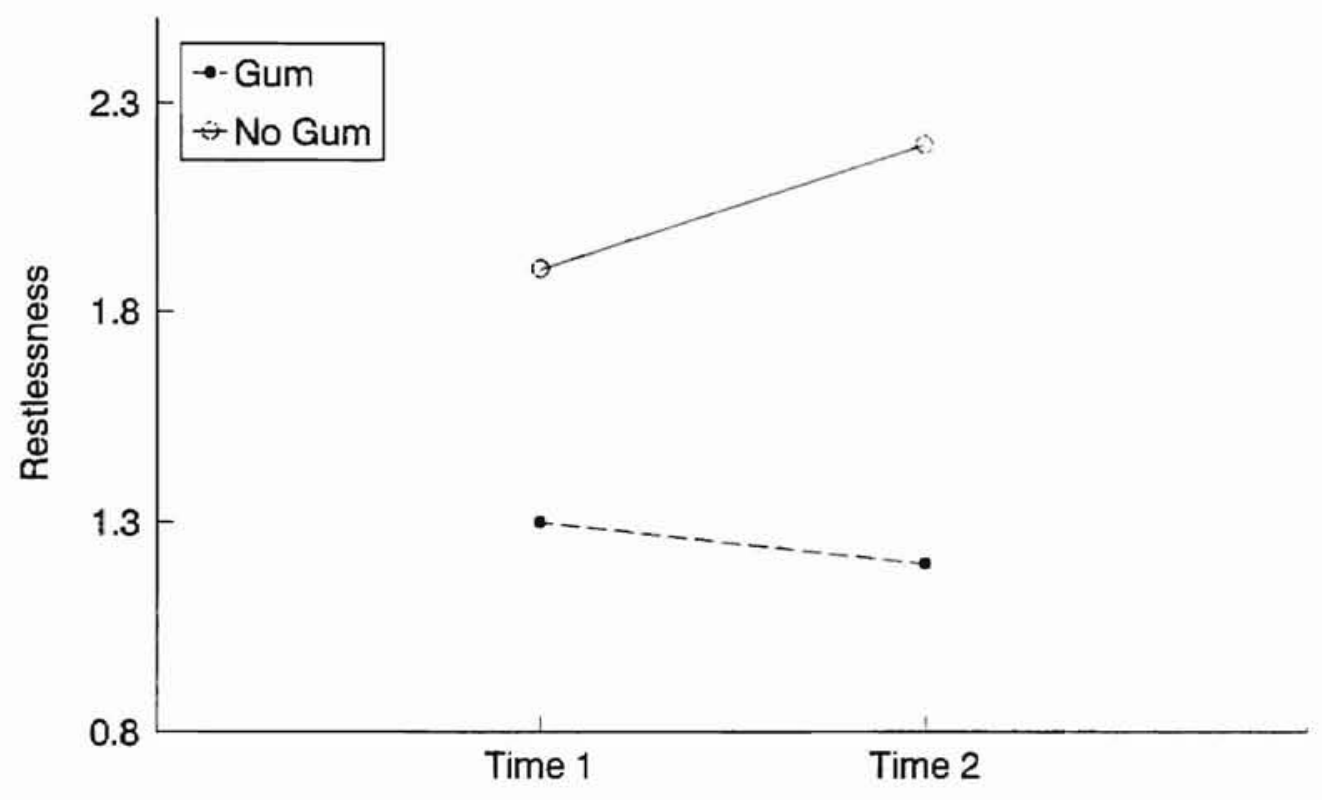




\section{VITA}

Lee M. Cohen

Candidate for the Degree of

Master of Science

Thesis: THE EFFECT OF CHEWING GUM ON TOBACCO WITHDRAWAL

Major Field: Psychology

Biographical:

Personal Data: Born in Encino, California, July 2, 1972, the son of Fred and Hazel Cohen.

Education: Graduated from Canyon High School, Canyon Country, California in June 1990; received Bachelor of Arts degree in Psychology from the University of California, San Diego, La Jolla, California in June, 1994.

Completed the requirements for the Master of Science degree with a major in Psychology at Oklahoma State University in May, 1996.

Professional Memberships: American Psychological Association, Southwestern Psychological Association, Society of Behavioral Medicine, Association for the Advancement of Behavior Therapy. 


\section{OKLAHOMA STATE UNIVERSITY INSTITUTIONAL REVIEW BOARD HUMAN SUBJECTS REVIEW}

Date: $03-27-95$

IRB\#：AS-95-052

Proposal Title: THE EFFECT OF CHEWING GUM ON TOBACCO WITHDRAWAL SYMPTOMS

Principal Investigator(s): Frank Collins, Lee Cohen

Reviewed and Processed as: Expedited

Approval Status Recommended by Reviewer(s): Approved

APPROVAL STATUS SUBJECT TO REVIEW BY FULI INSTTTUTIONAL REVIEW BOARD AT NEXT MEETING.

APPROVAL STATUS PERIOD VALID FOR ONE CALENDAR YEAR AFTER WHICH A CONTINUATION OR RENEWAL REQUEST IS REQUIRED TO BE SUBMITTED FOR BOARD APPROVAL.

ANY MODIFICATIONS TO APPROVED PROJECT MUST ALSO BE SUBMITTED FOR APPROVAL.

Comments, Modifications/Conditions for Approval or Reasons for Deferral or Disapproval are as follows:

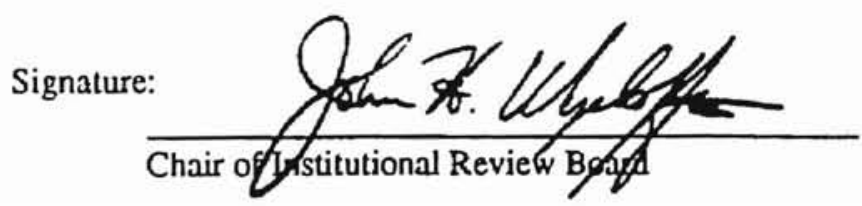

Date: April 19, 1995 